\title{
CHAPTER
}

\section{The great transition: Kuznets facts for family-economists}

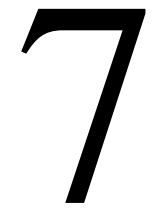

\author{
Jeremy Greenwood ${ }^{\mathrm{a}}$, Nezih Guner ${ }^{\mathrm{b}, *}$, and Ricardo Marto ${ }^{\mathrm{a}}$ \\ ${ }^{a}$ University of Pennsylvania, Philadelphia, PA, United States \\ ${ }^{\mathrm{b}} U A B, I C R E A$, BSE, Barcelona, Spain \\ *Corresponding author: e-mail address: nezih.guner@cem.es
}

\section{CONTENTS}

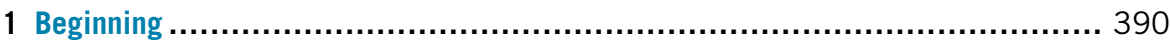

2 Kuznets facts for family-economists ................................................... 392

2.1 Kuznets fact 1 : the decline in work effort ........................... 392

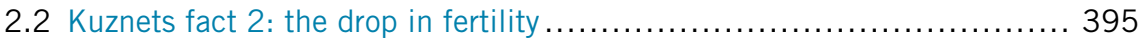

2.3 Kuznets fact 3 : the waning in marriage .............................. 397

2.4 Kuznets fact 4 : the descent in household size $\ldots \ldots \ldots \ldots \ldots \ldots \ldots \ldots \ldots \ldots . \ldots \ldots$

2.5 Kuznets fact 5: the waxing in educational attainment.................... 399

2.6 Kuznets fact 6: the shift from blue- to white-collar jobs ................. 399

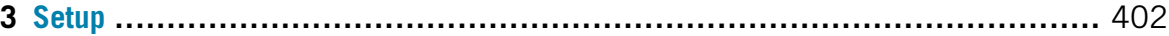

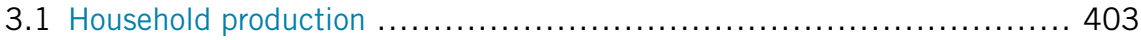

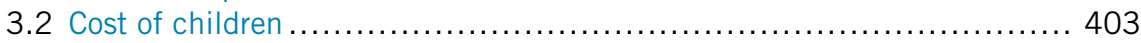

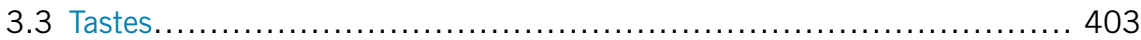

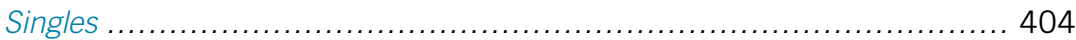

Marrieds ................................................................. 404

4 Decision problems...................................................................... 405

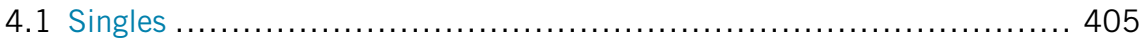

4.2 Married couples.................................................. 405

4.3 Married versus single life ....................................... 406

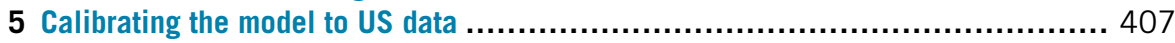

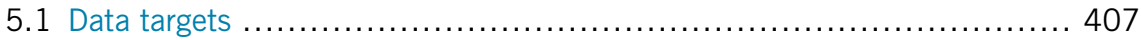

5.2 Fitting parameter values........................................... 409

Assigning parameter values using direct information........................ 409

Identifying parameter values using the first-order conditions-inner loop...... 412

Calibrating parameter values to maximize model fit-outer loop ............... 416

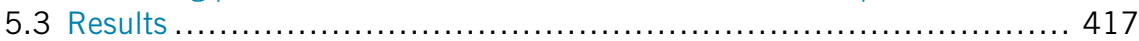

6 Propelling the great transition ..................................................... 419

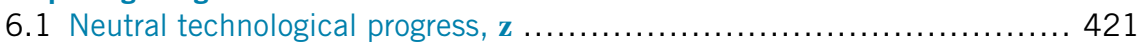

The Editors, three referees, and Jordan Peeples furnished useful comments. Claudio Luccioletti provided excellent research assistance. This research was supported by the National Science Foundation. 


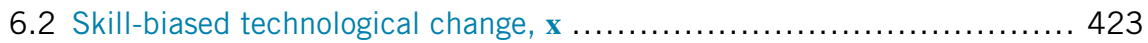

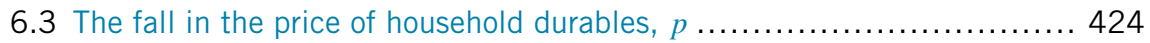

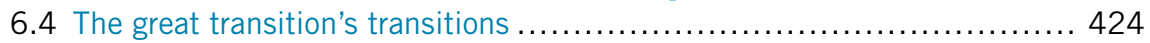

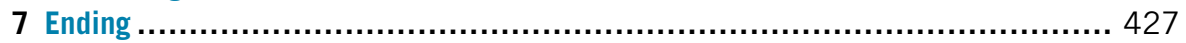

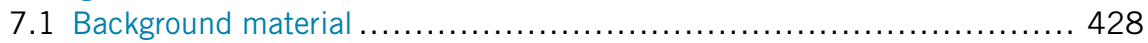

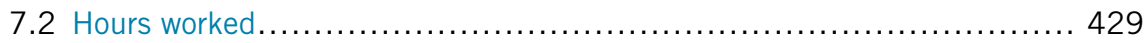

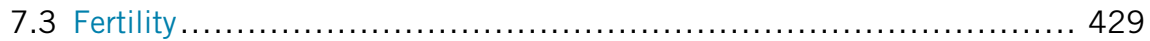

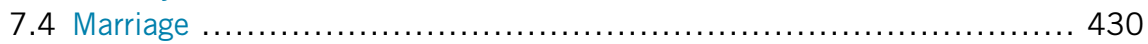

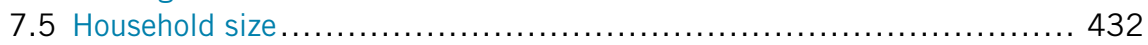

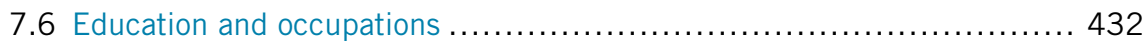

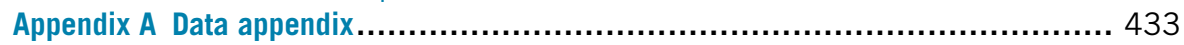

References....................................................................... 436

\section{Beginning}

In celebrated research Simon Kuznets (1957) documented the structural change that an economy goes through as it grows. In particular, he showed that as an economy evolves, there is a shift in the distribution of output away from agriculture toward manufacturing and after that a reallocation favoring services. Likewise, with economic development there is initially a decline in the share of agriculture in aggregate employment with labor being redirected into manufacturing and then eventually moving into services. Kuznets (1957) examined both time trends within countries as well as distributional variations in output and employment across countries according to their levels of development. ${ }^{1}$

The analysis has four key objectives. First, it follows in the footsteps of Kuznets (1957) by examining the structural change that the family goes through as an economy develops. This is done both across time and countries. Six Kuznets-style facts are presented: (1) the decline in work effort, (2) the drop in fertility, (3) the waning in marriage, (4) the descent in household size, (5) the waxing in educational attainment, and (6) the shift from blue- to white-collar jobs.

Second, a macroeconomic model of the family is developed and calibrated to see if it can simultaneously explain the above set of facts. Why take a macroeconomic approach? Macroeconomics is oriented toward explaining trends in aggregate time series, such as those enumerated above. Additionally, macroeconomic models are general equilibrium in nature and therefore incorporate interlinkages in the economy. For instance, technological progress in the economy affects wages, a general equilibrium effect. The effect on wages will impact the labor-supply decisions of men and women, which in turn will feedback on wages. The same is true for parents'

\footnotetext{
1 Kuznets was instrumental in developing the US National Income and Product Accounts. In his early thirties he oversaw, for the Bureau of Foreign and Domestic Commerce, the tallying of the first official estimates of GNP published in the report National Income, 1929-32 (Bureau of Foreign and Domestic Commerce, 1934).
} 
fertility and education decisions, as they will determine the supplies of skilled and unskilled labor in the economy. Also, the implementation of public policies is likely to have macroeconomic effects. Some causal impulses underlying the great transition are examined: neutral technological progress, skill-biased technological change, and process innovation in the production of labor-saving household durables. These forces affect the wages of skilled and unskilled labor. Both neutral and skill-biased technological change are important for explaining the rise in living standards between 1880 and 2020. Skill-biased technological progress is the primary driver of the decline in fertility and the rise in educational attainment; it encourages families to shift from having a large number of uneducated children toward a smaller number of educated ones. Process innovation in the production of household durables is the force underlying the decline in housework, the rise in married female labor supply, and the fall in marriage. The model can be used to assess the value of household production over time. Its value was as high as measured consumption expenditure in 1880 and dropped to about one-third of consumption expenditure by 2020 .

Third, the macroeconomic model of the family that is presented is all-inclusive in nature. This is important because current models of the family tend to focus on some subset of these facts, while ignoring the complementary set. Decisions about educational attainment, fertility, labor supply, and marriage are likely to be interconnected. Examples are: Children are a prime reason for marriage; Education and labor supply decisions are likely to be linked; Labor supply decisions within the family are intertwined with decisions about family size and marriage. Untangling these decisions in empirical work is a daunting task, and macroeconomic modeling can provide guidance on the mechanisms at work. The analysis illustrates how each of these decisions can be cast and explains them in a heuristic manner.

Fourth, the calibration procedure shows how the parameters governing tastes and technology can be backed out to match certain Kuznets facts. The trends in the macro data are very strong, implying that the signal-to-noise ratio is high. The response of educational attainment, fertility, labor supply, and marriage to technological progress will depend on various elasticities. For example, one might expect that the response of hours worked in the market to technological advance depends on the wage elasticity of labor supply. These elasticities will be functions of the model's parameters. The analysis illustrates how many of these parameters can be exactly identified from the first-order conditions connected with families' and firms' optimization problems. This is a theory-based identification strategy. The first-order conditions are also instructive for analyzing how the model will react in response to the three sources of technological advancement considered here.

One can think about this work as providing a tutorial on macroeconomic theorizing of the family and a primer on how to calibrate quantitative macroeconomic models of the family to fit aggregate data. A literature review is provided at the end. The review is oriented toward providing references for the ingredients used in, and the findings from, macroeconomic modeling of the family pertaining to the six Kuznets facts presented here. 


\section{Kuznets facts for family-economists}

Six key facts about the twentieth-century great transition are presented now. Data descriptions and sources are provided in the Data appendix.

\subsection{Kuznets fact 1: the decline in work effort}

There has been a dramatic decline in labor effort over the last two centuries, as Fig. 2.1 shows. $^{2}$ In 1830 the average full-time worker put in 69 hours of effort. This declined to 39 hours by 2000 . Historically speaking, it was mostly men that participated in the labor market. They had a workweek of 63 hours in 1900 versus 44 hours in 2018. Over time the labor-force participation rate for men has fallen. It was 97 percent in 1860 compared with 88 percent in 2018. By contrast, almost no women worked in 1860 (7 percent) while the majority did in 2018 (74 percent). The average workweek for women was 40 hours in 1940 and declined slightly to 38 hours in 2018. While historically women did not participate in the labor market as much as men, women did work in the home. In particular, in 1900 they spent 58 hours a week on cleaning, cooking, and laundry. This tumbled to just 11 hours by 2019, as Fig. 2.2 illustrates.

Now, one might think that poor countries today might resemble the United States of the past. If so, then there should be a negative relationship in a cross-section of countries between per-capita income and average weekly market hours. Likewise, time spent in housework should decline with per-capita income. It might be a bit wide-eyed to expect that the cross-country relationship observed today would match up exactly with the US historical time series (where time is replaced with per-capita income) because even the poorest countries today have appliances, computers, and machinery that were not available in the American past. As can be seen from Fig. 2.3, though, there is indeed a negative relationship between (logged) per-capita GDP and average weekly hours. The correlation coefficient between these two variables is -0.64 . There are also negative correlations between time spent on cleaning and percapita GDP and between time spent on cooking and per-capita GDP. The correlation coefficients are -0.31 and -0.78 , respectively.

As the need for household labor declined and as the workplace became more favorable to women, in part due to new appliances in the home and a shift from brain to brawn in the market sector associated with computerization and mechanization, there was an upswing in female labor-force participation across the world. This can be gleaned from the left panel of Fig. 2.4. Per-capita GDP and female labor-force participation are positively related, with a correlation coefficient of 0.48 between the two series. The waxing of female labor-force participation is stronger than it ap-

\footnotetext{
2 For a different perspective on hours worked both in the home and market see Ramey and Francis (2009).
} 

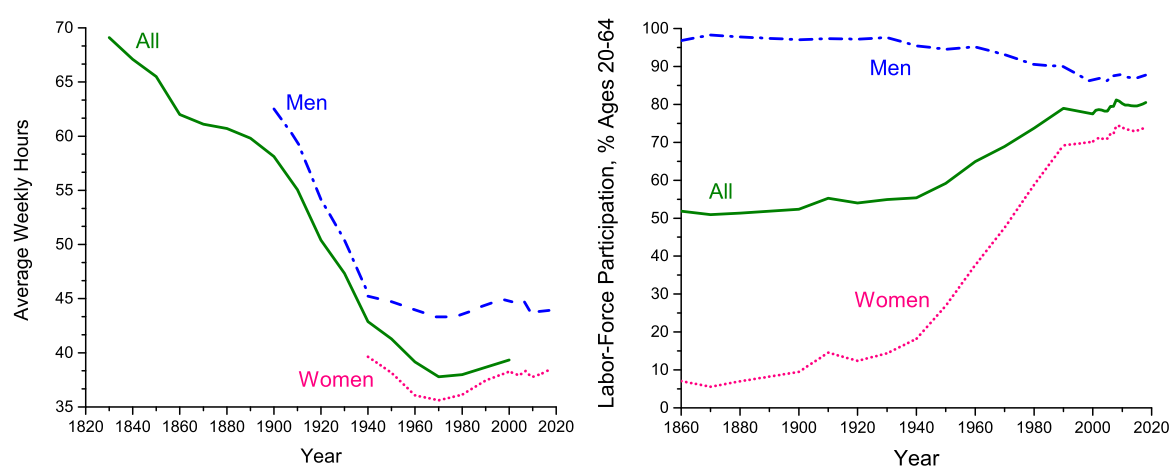

FIGURE 2.1 Average weekly hours and labor-force participation in the United States.

Note: The left panel shows the average number of hours worked per week per employed person in the United States for individuals ages 15 and above for data prior to 1940 and for the 20-to-64 age group starting in 1940. The right panel shows the labor-force participation rates of men and women ages 20 to 64 in the United States. The "All" series averages across both sexes.

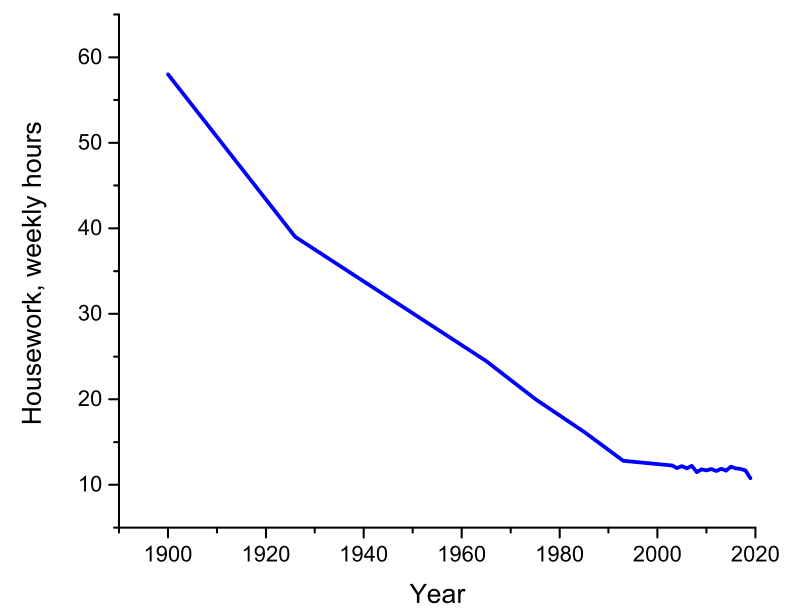

FIGURE 2.2 Housework in the United States.

Note: The plot shows the average number of hours spent per week in housework in the United States, which includes cleaning, cooking, and laundry. Data starting in 1965 are for women ages 20 to 64 .

pears in the scatter diagram. This is because technological innovation at home and in the workplace hits various countries at differing levels of GDP per capita, thereby muddying per-capita GDP's relationship with female labor-force participation. Additionally, one would expect female labor-force participation to peak and level off at 

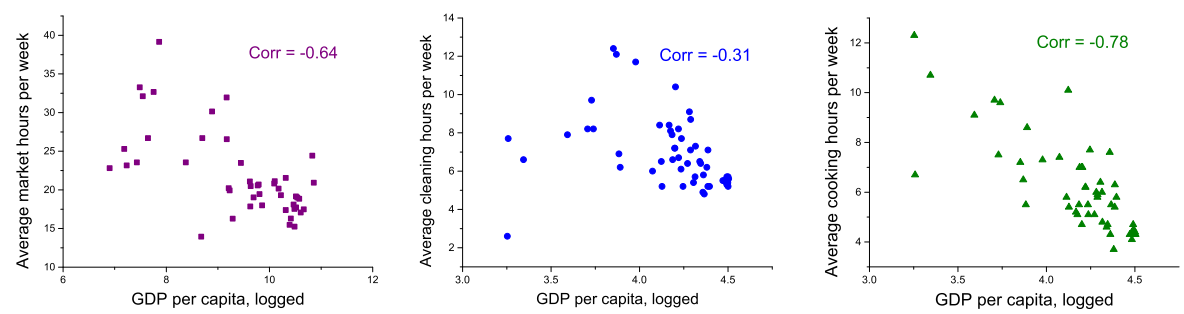

FIGURE 2.3 The cross-country relationship between per-capita GDP and hours worked, both in the market and at home.

Note: The left panel shows the relationship between the average number of hours worked per week for individuals 15 and older and real GDP per capita (logged) for 46 countries in 2005. The middle and right panels show the relationship between the average number of hours spent per week cleaning and cooking for the 15-to-64 age group, respectively, and real GDP per capita (logged) for 24 countries and multiple years (between 1974 and 2012).
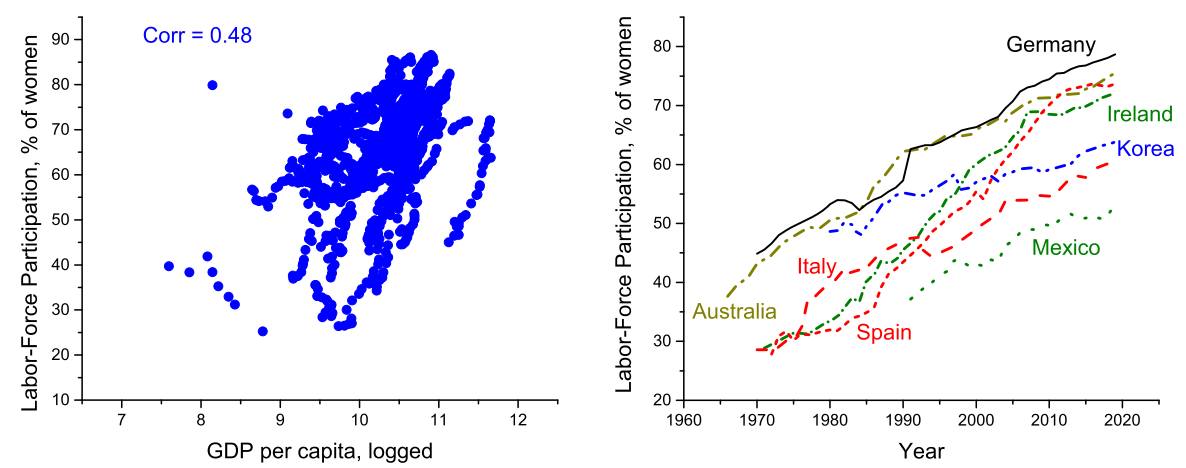

FIGURE 2.4 The cross-country rise in female labor-force participation, ages 20-64.

Note: The left panel shows the relationship between the labor-force participation of women ages 20 to 64 and real GDP per capita (logged) for 50 countries between 1990 and 2019 . The right panel shows the labor-force participation of women ages 20 to 64 over time for selected countries starting in the 1960s.

some point in time, as is the case for the United States. After leveling off the relationship between female labor-force participation and per-capita GDP would be flat. The right panel of Fig. 2.4 shows the rise in female labor-force participation over time for seven representative countries. As can be seen, the trends follow the US pattern.

Another manifestation of the decline in hours worked is the trend over the last century toward retiring at an earlier age. Although life expectancy was much shorter in the past, sixty percent of 80-year-old men in the United States still worked in 1850! This had fallen to just 6 percent by 2018, as Fig. 2.5, left panel, illustrates. 

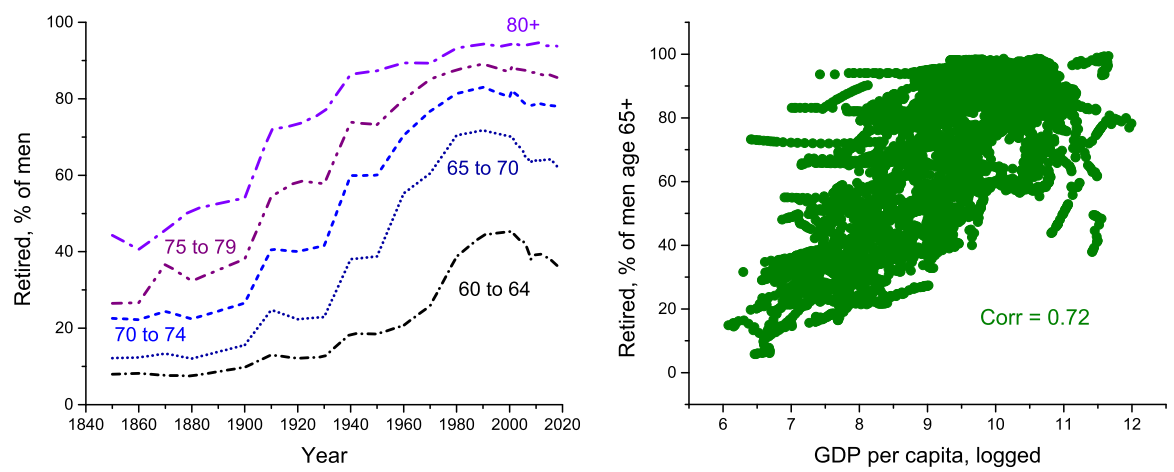

FIGURE 2.5 The trend toward earlier retirement.

Note: The left panel shows the fraction of men who are not in the labor force in the United States across 5-year age groups (60-64, 65-69, 70-74, 75-79, 80+) starting in 1850. The right panel shows the relationship between the fraction of men ages 65 and older who are not in the labor force and real GDP per capita (logged) for 173 countries between 1990 and 2019.

Over the course of the last century, there was a dramatic increase in the fraction of men in retirement for every age group over 60 . This stylized fact is also true across the world. In the cross-country data, the fraction of men retired after age 65 is positively related with GDP per capita, as can be seen in the right panel. A caveat is in order. As life spans increase in the modern era people may choose to delay retirement. Some evidence of this is seen in the US time series for the 60-to-65 and 65-to-70 age groups.

\subsection{Kuznets fact 2: the drop in fertility}

The track followed by fertility descended from 7.4 children per white woman in 1800 , to 4.2 in 1880 , and then to 1.6 kids in $2018 .^{3}$ The trend in the total fertility rate (TFR), shown in Fig. 2.6, was interrupted once by the baby boom, which occurred roughly between 1940 and 1971, with a peak of 3.6 kids in 1957. As can be seen, the secular decline in fertility swamps the rise during the baby boom years. Fertility decreases as a country becomes richer, as can be seen in Fig. 2.7 (left panel). The correlation coefficient between (the log of) per-capita GDP and the total fertility rate is -0.75 . The downward time trend in the crude birth rate (CBR) for seven representative countries is also shown (middle panel). Mexico displays the classic $\bigcap$-shaped demographic transition, where fertility first rises and then falls. At its peak in 1930 there were

\footnotetext{
3 Data for women of all races only started being continuously recorded in 1933. The figure is almost
} indistinguishable if all races are included after 1933. 


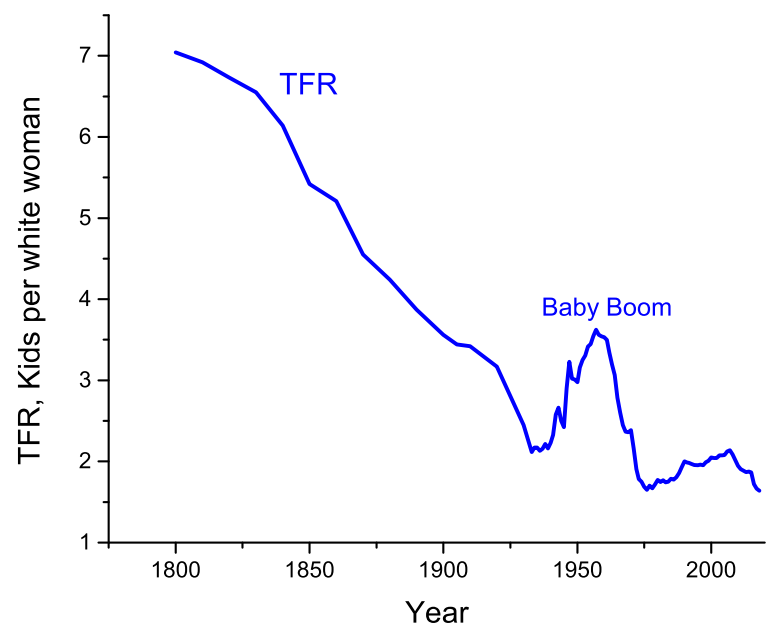

FIGURE 2.6 Fertility in the United States.

Note: The plot shows the total fertility rate (TFR) in the United States for white women ages 10 to 49 . The total fertility rate is the sum of birth rates for five-year age groups (ages 1014, 15-19, 20-24, 25-29, 30-34, 35-39, 40-44, 45-49) multiplied by 5.
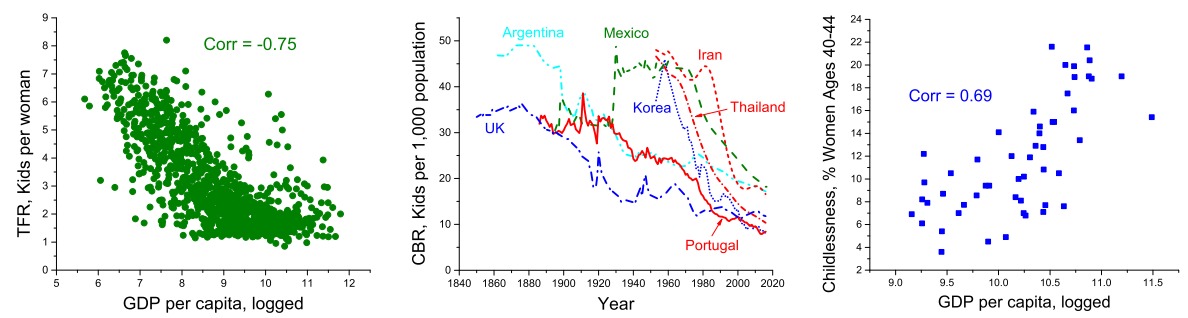

FIGURE 2.7 The cross-country decline in fertility.

Note: The left panel shows the relationship between the total fertility rate and real GDP per capita (logged) for 185 countries between 1990 and 2015. The total fertility rate is the sum of birth rates for five-year age groups (ages 15-19, 20-24, 25-29, 30-34, 35-39, 40$44,45-49$ ) multiplied by 5 . The middle panel presents crude birth rates (births per 1,000 women) for selected countries over time. The percentage of women, ages 40 to 44 , who haven't had a live birth is displayed in the right panel for 33 countries for various years in the 1990s and 2010s.

49 births per 1,000 population. By 2016 this had dropped to 18 . While the midtwentieth century baby boom for the United Kingdom is noticeable, it is swamped by the secular decline. Last, as a country becomes richer, the percentage of women in their forties who haven't had a live birth increases, displaying a correlation with per-capita GDP of 0.69 (right panel). 

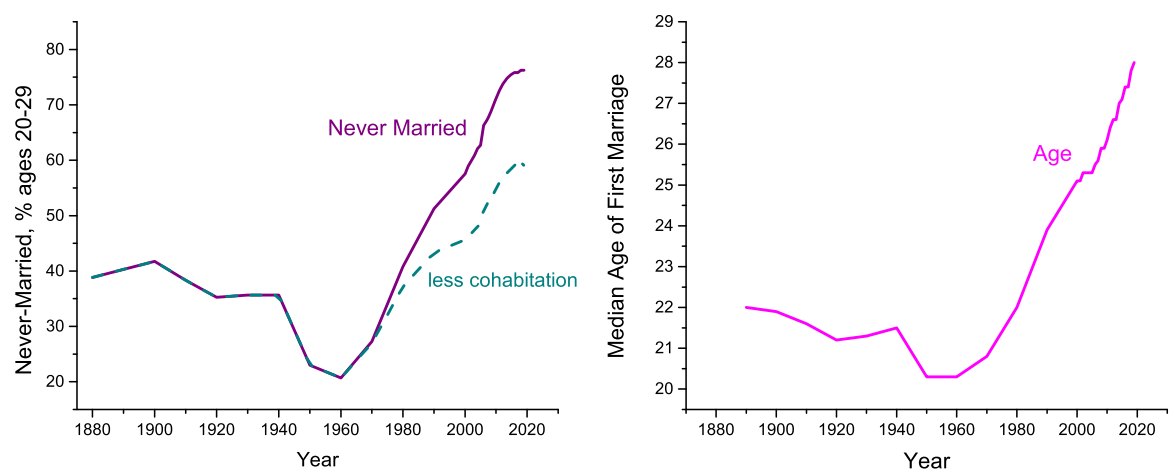

FIGURE 2.8 Marriage in the United States.

Note: The left panel shows the fraction of women, ages 20 to 29 , who never married (the denominator excludes women who are separated, divorced, or widowed). A series is also plotted where cohabiting never-married women are subtracted off of never-married women. The median age at first marriage for women is displayed in the right panel.

\subsection{Kuznets fact 3: the waning in marriage}

In 1880 only 39 percent of women in the 20-to-29 age group had never been married; direct attention to the left panel of Fig. 2.8. ${ }^{4}$ This jumped up to 76 percent by 2019. The growth in never-married women was linked to an increase in the median age of marriage from 22 years in 1890 to 28 in 2019-right panel. Around the baby boom years there was a burst in marriage with an associated drop in the median age of marriage. The left panel of Fig. 2.8 also shows a plot where never-married women who are cohabiting have been netted out. The difference between the two lines gives the percentage of never-married cohabiting women. As can be seen, cohabitation has increased in recent years. In 2019 about 17 percent of never-married women were cohabiting.

Fig. 2.9 tracks the composition of US households over time. The fraction of US households that were married contracted continuously, especially married households with children. Correspondingly, the fraction of households made up by singles grew significantly, with a distinct rise in single households with children.

Waning marriage shows up in the cross-country data as well. The fraction of women ages 20 to 24 that are never married rises with (the log of) real per-capita income. The correlation between the two series is 0.83-see Fig. 2.10, left panel.

\footnotetext{
4 The fraction of never (or ever) married women in the 20-to-29 age group captures the aggregate trends for marriage in the US very well. It is highly correlated with alternative measures, such as the fraction of women between ages 18 and 64 who are married or the fraction of adult life spent in marriage; see Greenwood and Guner (2009) for such alternative measures. The odds of being never married decrease with age. Focusing on ever-married women at a later age would disguise the diminishing importance of marriage as a large and relatively stable fraction of adults get married at least once.
} 


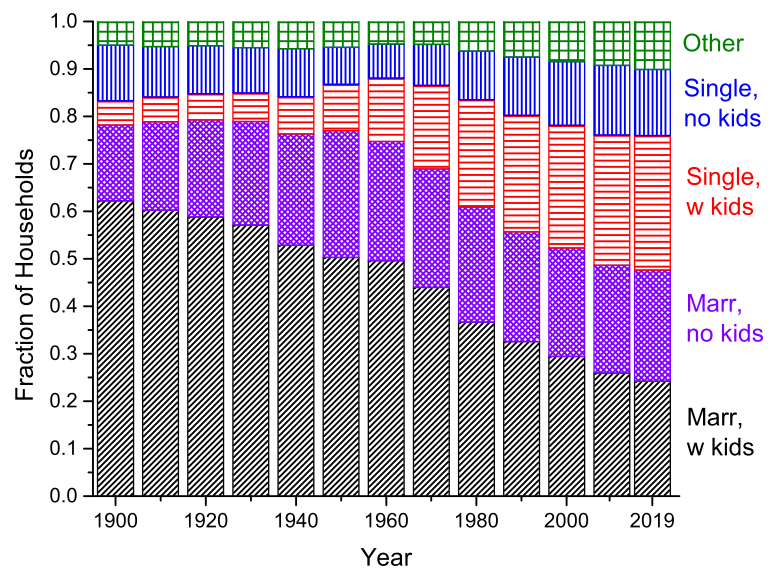

FIGURE 2.9 Composition of households in the United States.

Note: The figure shows the fraction of US households in different living arrangements (the other category includes other family and nonfamily households).
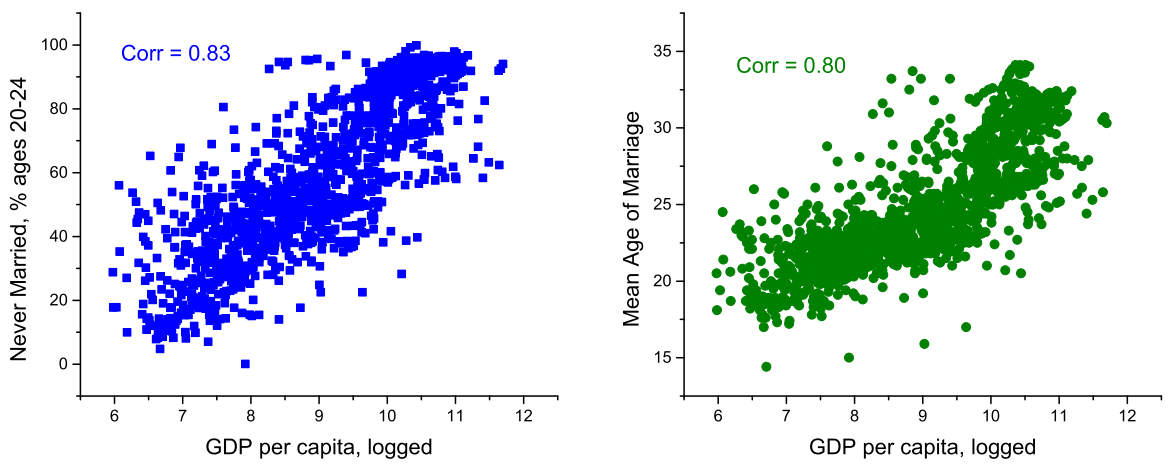

FIGURE 2.10 The cross-country relationship between per-capita GDP and marriage.

Note: The left panel shows the relationship between the fraction of women, ages 20 to 24 , who never married and real GDP per capita (logged) for 196 countries between 1990 and 2019. The right panel shows the relationship between women's mean age at first marriage (among persons who ever marry) and real GDP per capita (logged) for 195 countries between 1990 and 2019.

Similarly, the mean age of first marriage (right panel) climbs with income, with a correlation coefficient of 0.80 .

\subsection{Kuznets fact 4: the descent in household size}

Associated with the drop in fertility and rise in the number of singles has been a descent in household size, both in the United States and across countries. In 1850 

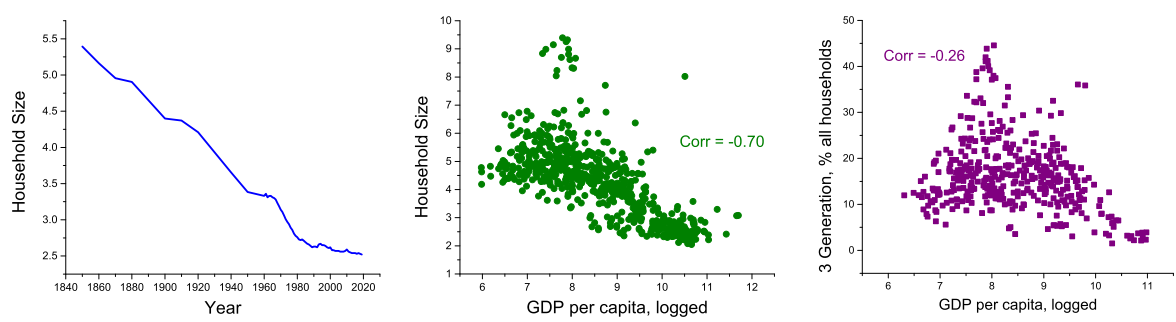

FIGURE 2.11 Household size in the United States and across countries.

Note: The left panel shows average household size in the United States. The middle panel displays the relationship between average household size and real GDP per capita (logged) for 151 countries between 1990 and 2018. The right panel presents for 106 countries covering various years the relationship between the percentage of households where three generations are residents and real per-capita GDP (logged).

there were roughly 5.4 people living in the average American household, compared with 2.5 in 2019. Across countries there is a negative association between per-capita GDP and household size, which can be seen with a correlation of -0.70 in Fig. 2.11. Also, the percentage of households where three generations of family members live together declines with per-capita real GDP, although the correlation is weaker $(-0.26)$.

\subsection{Kuznets fact 5: the waxing in educational attainment}

A child born in the United States in 1876 would have had 7.7 years of schooling by age 35, while one born in 1975 would have had 14.2; see Fig. 2.12. Therefore, years of schooling roughly doubled over the last century. In 1869 only 1.3 percent of Americans, ages 18 to 24, were enrolled in an institution of higher education, while 57 percent were in 1995 . Move on now to the cross-country data and direct attention to Fig. 2.13. Years of schooling rise with a country's level of per-capita GDP; the correlation coefficient is 0.85 . Likewise, the percentage of the population that completed a tertiary education moves up with per-capita GDP, with a correlation of 0.71 . The cross-country evidence is simpatico with the US time-series evidence.

\subsection{Kuznets fact 6: the shift from blue- to white-collar jobs}

With the introduction of electricity and the internal combustion engine, the need for physical labor declined. This led to a dramatic shift in labor force away from bluecollar jobs toward white-collar ones for both men and women. This shift is displayed in Fig. 2.14. As can be seen, 88 percent of the male labor force labored in blue-collar jobs in 1860 . By 2018 this had dropped to 37 percent. The shift was even stronger for women. Today only 10 percent of working women are in blue-collar jobs compared with 87 percent in 1860 . Not surprisingly, over the entire period there is a proclivity of women relative to men to favor white-collar jobs over blue-collar ones. The same trend is true in the cross-country data. As a country's per-capita GDP rises, so does 


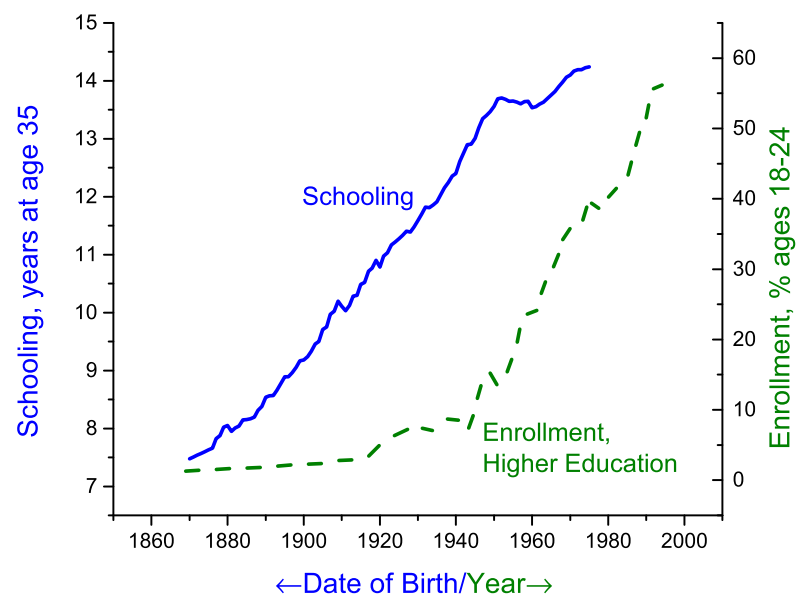

FIGURE 2.12 Educational attainment in the United States.

Note: The plot shows the average number of years of schooling in the United States measured at age 35 by date of birth (solid line) and the fraction of the population, ages 18 to 24 , enrolled in tertiary education (dashed line).
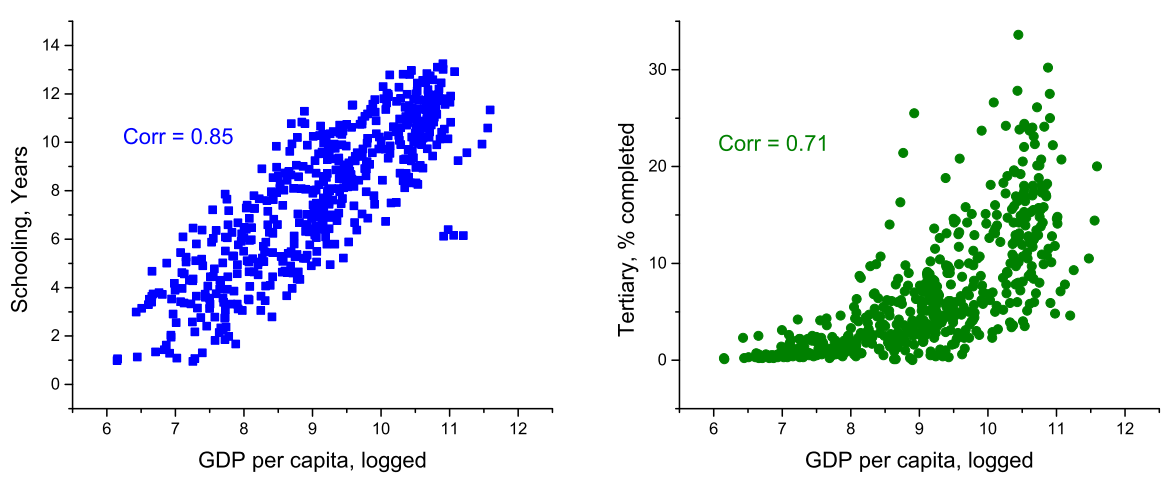

FIGURE 2.13 The cross-country relationship between per-capita GDP and educational attainment.

Note: The left panel shows the relationship between the average number of years of schooling for the 15-to-64 age group and real GDP per capita (logged) for 105 countries between 1990 and 2018. The right panel shows the relationship between the fraction of the population ages 15 to 64 who completed tertiary education and real GDP per capita (logged) for 105 countries between 1990 and 2018.

the fraction of the labor-force working in white-collar jobs. This fact is true for both men and women; see Fig. 2.15. Women are more likely to work in white-collar jobs than men, though. 


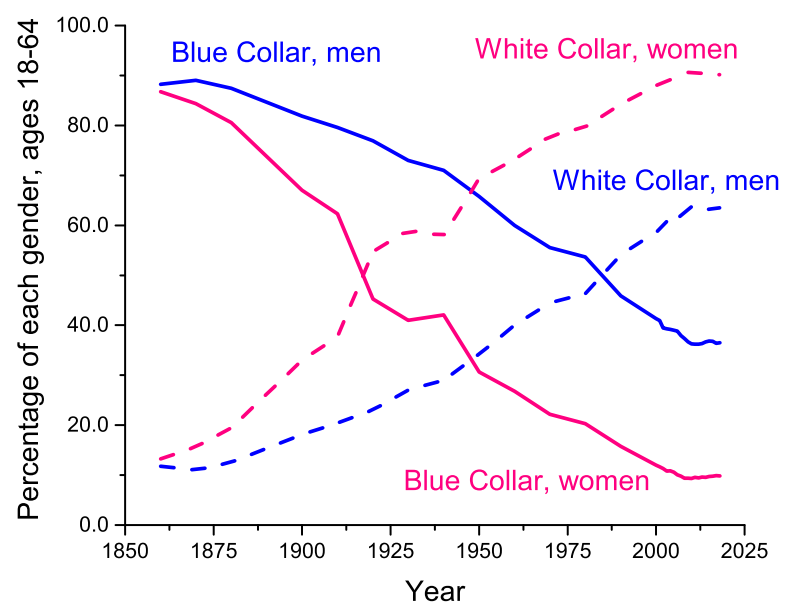

FIGURE 2.14 Occupations in the United States for men and women.

Note: The plot shows the percentage of men in blue- vs. white-collar occupations and the percentage of women in blue- vs. white-collar occupations. White-collar jobs comprise the managerial and professional specialty occupations as well as the technical, sales, and administrative support occupations. Blue-collar jobs comprise the services occupations, the farming, forestry, and fishing occupations, the precision production, craft, and repair occupations, and the operators, fabricators, and laborers occupations.
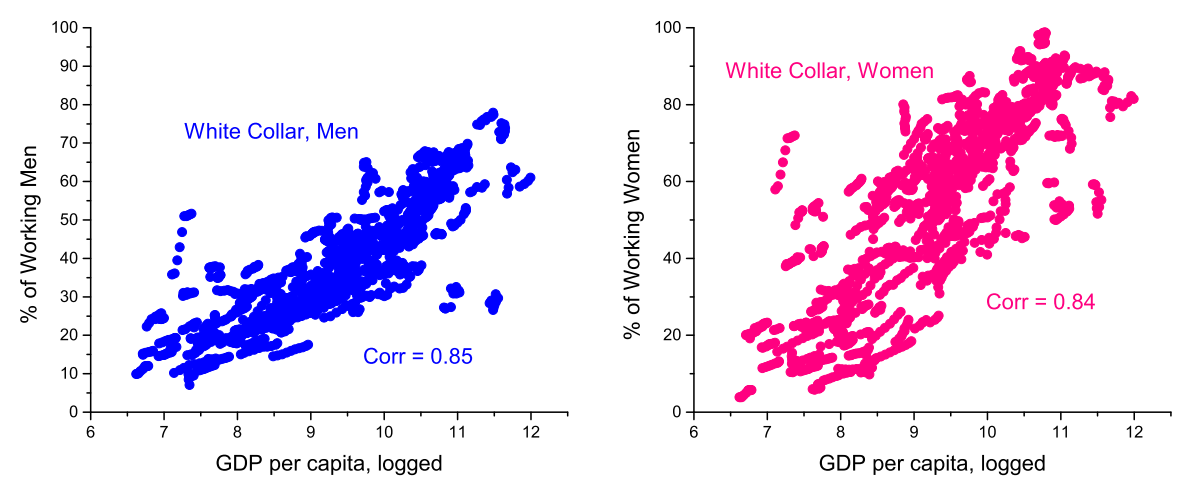

FIGURE 2.15 The cross-country relationship between per-capita GDP and white-collar jobs.

Note: The left panel shows the relationship between the fraction of working men (for most countries ages 15 and older) in white-collar occupations and real GDP per capita (logged) for 186 countries between 2010 and 2018. The right panel shows the relationship between the fraction of working women in white-collar occupations and real GDP per capita (logged) for 186 countries between 2010 and 2018. 


\section{Setup}

The father of family economics is Gary S. Becker. A compilation of his work is contained in Becker (1991). The work here follows in his footsteps. To keep things simple, the framework is static. There are two types of households in the economy, married and single. An adult in a household lives for one period and has one unit of time. A single household can split its unit of time between three uses: household production, $h$, leisure, $l$, and toiling in the market, $t \equiv 1-l-h$. A married couple has two units of time. They may devote some of this time to raising children, both for basic childcare and educating their kids. All children within the household are identical. In terms of time, a child costs $b$ in basic childcare and $e$ in education. So, a married couple has five uses for their time: basic childcare for $k \geq 0$ kids, or $b k$; educating $k$ children, $e k$; household production, $h$; leisure, $l$; and toiling in the market, $t \equiv 2-b k-e k-h-l$. An adult has one unit of raw talent that is divided between brain and brawn. This split, $s \in[0,1]$, was decided earlier in life by the adult's parents. A unit of brain is paid $v$ while a unit of brawn receives $u$. Brain is paid more than brawn so that $v>u$. The market wage for a unit of labor, $w=s v+(1-s) u$, depends on how a person's skill endowment is split between brain and brawn.

Labor income is used to purchase market consumption, $c$, and household durables, $d$. Market consumption is the numeraire good with a price of one. Durable goods, $d$, are mixed with household labor, $h$, to produce nonmarket goods, $n .^{5}$ The per-unit price of a household durable is $p$.

At the beginning of adult life a single is matched with another single. At that point in time, they draw a common joy shock for the relationship, $j$. The couple then decides immediately whether to marry or not. In addition to marital joy, $j$, marriage offers the possibility of children, $k$, as well as some scale economies from pooling resources. The extent of the scale economies from pooling resources is regulated by a household equivalence scale, $\varepsilon \in[0.5,1.0]$. Specifically, the household equivalence scale converts total consumption into consumption per adult, so in a married household the per-adult consumptions of market and nonmarket goods are $\varepsilon c$ and $\varepsilon n$.

The only meaningful source of heterogeneity in the analysis is the difference between married and single households. The framework abstracts from differences across individuals, such as education, occupation, and race. As a result, it can't address the questions of who stays single, who marries, and who marries with whom. Becker (1973) laid the foundations for analyzing assortative mating in marriage markets by partners' characteristics. The trends in assortative mating and its impact on inequality and intergenerational mobility have gained renewed interest in recent years; Chiappori et al. (2020) provide a recent review.

\footnotetext{
5 Note that $h$ can be different from $h$ above, when there is child labor in the home.
} 


\subsection{Household production}

Nonmarket goods, $n$, are produced in accordance with the following household production function

$$
n=\left[\theta d^{\sigma}+(1-\theta) h^{\sigma}\right]^{1 / \sigma}, \text { with } \sigma \leq 1,
$$

where $d$ represents the input of household durables in production and $\mathrm{h}$ denotes the amount of household labor. For a single household their labor is just the time spent on housework; i.e., $\mathrm{h}=h$. For a married household $\mathrm{h}$ might include the physical labor of children. Specifically, for a married household with $k$ children, let $h=h+\chi k$, where $\chi$ represents the productivity of a child in housework. Historically, children did some work in the home. As an economy develops, the need for child labor diminishes. This could transpire because better appliances lower the burden of housework. Additionally, increased schooling reduced the time that a child could devote to housework. This is represented here by a drop in the value for $\chi$; i.e., $\chi$ is allowed to change over time. Child labor operates to reduce the cost of children, which has implications for fertility.

The parameter $\sigma$ plays an important role in the analysis. It controls the degree of substitutability between durables and labor in household production. A high value for $\sigma$ implies that durables and labor can easily be substituted. In this situation household durables are labor saving. So, a decline in the price of durables, $p$, will induce households to replace labor, $\mathrm{h}$, with capital, $d$, in the home. The parameter $\theta$ denotes the share of durables in household production; it plays a much lesser role in the analysis.

The notion of household production was first introduced into economics by Reid (1934). Her idea was formalized by Becker (1965) thirty years later. Reid (1934) speculated that labor-saving household capital could reduce the amount of time spent on housework, but the limited evidence at the time suggested a modest effect-see Reid's Table XIII.

\subsection{Cost of children}

Only married households have children. There are two costs of raising children: basic childcare and education. The time cost per kid for basic childcare is $b$. Thus, the cost of basic childcare for $k$ children is just $b k$. Each child has one unit of undeveloped talent. Parents can choose how to split their child's talent endowment between brain and brawn. This determines a child's future wage. Let $s \in[0,1]$ be the fraction that is allocated to brain. The time cost of educating a child, or $e$, is given by

$$
e=\gamma s
$$

\subsection{Tastes}

Preferences for married and single households are now specified. 


\section{Singles}

Tastes for a single are distributed over their consumption of market goods, $c$, nonmarket goods, $n$, and leisure, $l$. Their utility function reads

$$
\alpha \frac{c^{1-\rho}-1}{1-\rho}+\beta \frac{n^{1-v}-1}{1-v}+(1-\alpha-\beta) \frac{l^{1-\lambda}-1}{1-\lambda} .
$$

Here $\alpha, \beta$, and $1-\alpha-\beta$ are the weights attached to the utilities from the consumptions of market goods, nonmarket goods, and leisure. The exponents on these utility terms, or $\rho, v$, and $\lambda$, control the concavity of the utility terms. As will be seen, these exponents (or inverse elasticities) are important for governing the rate of change over time in of utility function's arguments, while the weights can be thought of as determining the level of an argument for some baseline period.

\section{Marrieds}

For a married household, tastes are defined over their consumption of market goods, $c$, nonmarket goods, $n$, leisure, $l$, the number of children, $k$, and their children's future wage rate, $s v+(1-s) u$. As can be seen, the future wage for a child depends on their skill level, $s$. The utility function for a married household is specified as

$\alpha \frac{(\varepsilon c)^{1-\rho}-1}{1-\rho}+\beta \frac{(\varepsilon n)^{1-v}-1}{1-v}+\delta \frac{l^{1-\lambda}-1}{1-\lambda}+\psi \frac{k^{1-\kappa}-1}{1-\kappa}+\xi \frac{[s v+(1-s) u]^{1-\zeta}-1}{1-\zeta}$,

where again, $\varepsilon \in[0.5,1.0]$ is a household equivalence scale. When $\varepsilon=0.5$ there are no economies of scale in consumption. Alternatively, if $\varepsilon=1.0$, then consumption is a full public good. The weight on the utility from leisure for a married household, $\delta$, differs from a single one, $1-\alpha-\beta$; it's hard to know how the utility of husband and wife should be aggregated in a household. When the utility terms for the number of children, $\psi\left(k^{1-\kappa}-1\right) /(1-\kappa)$, and their skill level, $\xi\left\{[s v+(1-s) u]^{1-\zeta}-1\right\} /(1-$ $\zeta)$, are positive, this adds to the value of married life over single life.

The analysis here is purposefully kept simple by assuming that couples behave in single-minded fashion with one utility function. That is, a unitary model of the household is used. Collective models of the household let members have different tastes, but assume that the decision process by the partners lead to Pareto-efficient allocations. Chiappori (1988) focuses on the testable implications of efficient household decisions without imposing a particular decision process. ${ }^{6}$ Manser and Brown (1980) and McElroy and Horney (1981) consider alternative bargaining solutions between partners with explicit threat points. The threat point in bargaining could be divorce. Lundberg and Pollak (1993) define the threat point as the utility level couples would obtain if they do not cooperate. There is now sizable empirical evidence suggesting that who has the money in the household matters for household decisions-see Lundberg et al. (1997) for a well-known study.

\footnotetext{
6 Pareto efficiency can also be imposed in a dynamic setting, as in Voena (2015). Chiappori and Mazzocco (2017) provide a recent review.
} 


\section{Decision problems}

The decision problems for married and single households are now cast. The choice to either marry or remain single is then addressed.

\subsection{Singles}

The budget constraint for singles is

$$
c+p d=w(1-h-l)
$$

where the lefthand side represents the person's expenditure on market consumption and durables while the righthand side specifies their labor income. In the utility function for a single (3.3), substitute out for market consumption, $c$, using the budget constraint (4.1), and for nonmarket goods, $n$, using the household production function (3.1) while noting that $\mathrm{h}=h$. The maximization problem for singles then formulates as

$$
\begin{array}{r}
S=\max _{d, h, l}\left\{\alpha \frac{[w(1-h-l)-p d]^{1-\rho}-1}{1-\rho}+\beta \frac{\left[\theta d^{\sigma}+(1-\theta) h^{\sigma}\right]^{(1-v) / \sigma}-1}{1-v}\right. \\
\left.+(1-\alpha-\beta) \frac{l^{1-\lambda}-1}{1-\lambda}\right\} .
\end{array}
$$

The variable $S$ gives the maximal level of utility that a single can attain.

Singles do not have children in analysis. This is at odds with the real world. The fraction of households comprised of singles with children has grown substantially since 1900, as Fig. 2.9 shows. In a now classic book, McLanahan and Sandefur (1994) document how children growing up in single parent families fare worse in life than those growing up in two-parent ones. Greenwood et al. (2003) examine the plight of children in lone-parent families in the context of a marriage model where married, divorced, and never-married households have children.

\subsection{Married couples}

The budget constraint for married households reads

$$
c+p d=w(2-b k-\gamma s k-h-l) .
$$

Their budget constraint is similar to the one for singles except that a married couple has two units of time that must also be used for basic childcare, $b k$, and educating children, $e k=\gamma s k$. A married couple's maximization problem is

$$
M=\max _{d, h, l, k, s}\left\{\alpha \frac{\varepsilon^{1-\rho}\{w[2-b k-\gamma s k-h-l]-p d\}^{1-\rho}-1}{1-\rho}\right.
$$




$$
\left.\begin{array}{r}
+\beta \frac{\varepsilon^{1-v}\left[\theta d^{\sigma}+(1-\theta)(h+\chi k)^{\sigma}\right]^{(1-v) / \sigma}-1}{1-v}+\delta \frac{l^{1-\lambda}-1}{1-\lambda} \\
+\psi \frac{k^{1-\kappa}-1}{1-\kappa}+\xi \frac{[s v+(1-s) u]^{1-\zeta}-1}{1-\zeta}
\end{array}\right\} .
$$

In formulating this problem, $c$ and $n$ have been eliminated from (3.4) by using (4.3) and (3.1) while noting that $\mathrm{h}=h+\chi k$. The variable $M$ gives the economic value of marriage. The economic values of married and single lives, $M$ and $S$, play important roles in the marriage decision, as is discussed shortly. The first-order conditions connected with the time allocations in problem (4.4) are presented in Section 5. Important intuition about how the model operates in response to technological progress can be gleaned from these first-order conditions. Additionally, they can be used in a theory-based identification strategy for assigning parameter values when matching the model with the US data.

Fertility is modeled here along the lines of Razin and Ben-Zion (1975), who assume that children are goods that enters the utility function. The modern theory of education starts with Ben-Porath (1967). He formulated a model where individuals can spend time studying to accumulate human capital. Often, people interpret the full time spent on training at the beginning of life in his model as schooling. An important antecedent of Ben-Porath (1967) is Mincer (1958), who related schooling with income. In famous work, Becker and Lewis (1973) formulate the tradeoff between the quality and quantity of children, where quality refers to the level of human capital that a child is endowed with from their parents.

In the current analysis, men's and women's times are perfectly substitutable in home and market work. This retains the representative agent structure of the typical macro model. When the framework is matched with time-use data in Section 5, the time spent on basic child care, educating children, housework, and market work is tallied up in a married household across husbands and wives to get the total time spent by the household for each time category. Modeling the division of labor across men and women within a married household is beyond the scope of the current analysis. An early example of work concerning the division of labor within a married household is contained in Becker (1991, Chapter 2). Greenwood et al. (2003) model this in a framework where husband and wife Nash bargain. They report the time allocations for their model and discuss how this compares with data.

\subsection{Married versus single life}

A single is matched with another single at the beginning of adult life. Upon meeting they draw a common joy shock, $j$. The value of married life is then given by $M+j$, where the economic value of marriage, $M$, is defined by (4.4). The value of single life is provided by $S$ in (4.2). The joy shock, $j \in \mathbb{R}$, is drawn from a Gumbel distribution, $G(j)$, defined as:

$$
G(j)=\operatorname{Pr}(\tilde{j} \leq j)=\exp \left\{-\exp \left[-\frac{(j-\mathrm{a})}{\mathrm{d}}\right]\right\} \text {, with } \mathrm{d}>0,
$$


where a and $\mathrm{d}$ are the location and scale parameters, and $\tilde{j}$ denotes a random draw for $j$.

The decision to marry formulates as

$$
\begin{array}{ll}
\text { Marry, } & \text { if } M+j \geq S \\
\text { Single, } & \text { if } M+j<S
\end{array}
$$

The threshold level of joy, $j^{*}$, at which a person is indifferent between marriage and single life is given by $j^{*}=S-M$. While married households have different levels of joy, $j \geq j^{*}$, this doesn't play any purposeful role in the analysis. What is important is how the threshold level of joy, $j^{*}$, changes with shifts in the economy. Let $\mathrm{m}$ denote the fraction of the population that is married. The fraction of the population that is single (or unmarried), $1-\mathrm{m}$, is

$$
1-\mathrm{m}=G\left(j^{*}\right)=\exp \left\{-\exp \left[-\frac{\left(j^{*}-\mathrm{a}\right)}{\mathrm{d}}\right]\right\}=\exp \left\{-\exp \left[-\frac{(S-M-\mathrm{a})}{\mathrm{d}}\right]\right\} .
$$

The shape of the distribution function $G(j)$ will regulate flows into and out of marriage in response to shifts in the relative value of single life, $S-M$. Now, if the economic value of marriage exceeds the value of single life, so that $M>S$, then the threshold value for marriage, $j^{*}$, is negative. This implies that some people marry purely for economic reasons.

In contrast to the simple model presented here, marriage decisions are forwardlooking and take into account possibilities of divorce and remarriage in the future. The first search model of marriage and divorce with such features was developed by Mortensen (1988). Greenwood and Guner (2009) simulate a search model to see if it can match the trends in marriage and divorce since World War II. Dynamic models of marriage and divorce are used today to study a host of issues including the rise in assortative mating, the impact of changing divorce laws, and single motherhood.

\section{Calibrating the model to US data}

Can the above model match the Kuznets facts discussed in Section 2? To address this question, the analysis focuses on two periods: namely, 1880 and 2020. The set of targeted facts is fertility, schooling, housework, market work, and the fraction of the population that is single (or equivalently married). In order to match the set of data targets, values must be assigned to the model's various parameters. Some parameters' values can be directly imposed from information that is available while others are selected to maximize the fit of the model with respect to the data targets.

\subsection{Data targets}

The data targets are enumerated now. Unless mentioned, all definitions and sources for the data targets are the same as in Section 2 and are provided in the Data appendix. 
1. Fertility: The targets here are the total fertility rates for white women in 1880 and 2018. Therefore, the objective is to attain $k_{1880}=4.24$ and $k_{2020}=1.64$.

2. Market work: The average market workweek for a married household in 1880 is taken to be 68.82 hours, while for 2020 it was 66.91 hours. The number for 2020 corresponds to total market work by both a husband and wife ages 20 to 64 conditional on one person being employed, as recorded in the American Community Survey in 2019. While hours worked in the market declined over time for married men, they rose for married women resulting in the average workweek across both men and women being stable over time. There are 112 nonsleeping hours per adult in a week, so a married household will have $2 \times 112=224$ hours. Thus, for a married household, the goal is to match $t_{m, 1880}=2 \times 68.82 / 224$ and $t_{m, 2020}=2 \times 66.91 / 224$; recall that a married household has two units of time, whereas a single household has one. The 1880 and 2020 targets for the average market workweek for a single household are 40.26 and 33.83 hours. For 2020 the number is taken from the American Community Survey and is the average over all singles ages 20 to 64 in 2019. Therefore, for a single household, the targets are $t_{s, 1880}=40.26 / 112$ and $t_{s, 2020}=33.83 / 112$. To obtain the numbers for 1880 an inference is made. Specifically, Vandenbroucke (2009) reports that the average workweek (across both married and single individuals who worked) in 1880 was 60.7 hours. Therefore, $m_{1880} \times h r s_{m, 1880}+\left(1-m_{1880}\right) \times h r s_{s, 1880}=60.7$. Now, boldly assume that the married-to-single ratio of market time was the same in 1880 as is documented for 1940 by the Census, which is the earliest Census year for which hours-worked data are available. Then, one can write

$$
\mathrm{hrs}_{\mathrm{s}, 1880}=60.7 \div\left[m_{1880}\left(\mathrm{hrs}_{\mathrm{m}, 1940} / \mathrm{hrs}_{\mathrm{s}, 1940}\right)+\left(1-m_{1880}\right)\right],
$$

and

$$
h r s_{m, 1880}=\left[60.7-\left(1-m_{1880}\right) h r s_{s, 1880}\right] / m_{1880},
$$

where $\mathrm{hrs}_{\mathrm{m}, 1940} / \mathrm{hrs}_{\mathrm{s}, 1940}=41.94 / 24.53$. This calculation results in $\mathrm{hrs}_{\mathrm{m}, 1880}=$ 68.82 and $h s_{s, 1880}=40.26$.

3. Housework: Lebergott (1993) estimated that 58 hours a week was spent on housework-cleaning, laundry, and meals-in 1900. Assume that this number represents total housework in 1900 by both husband and wife. This number is somewhat speculative, but only 3 percent of households had electricity at this time. No one had refrigerators, vacuum cleaners, washing machines, and the like. According to Lebergott (1993), scrub boards were used to clean clothes by 98 percent of households with only 1 percent using a commercial laundry. By 2019 the total amount spent on housework by both husband and wife ages 20 to 64 had declined to 17.45 hours according to the data recorded in the American Time Use Survey. Given these facts, set the targets for a married household to $h_{m, 1880}=2 \times 58 / 224$ and $h_{m, 2020}=2 \times 17.45 / 224$. Data from the American Time Use Survey suggest that a single household (ages 20 to 64) spent 6.41 hours per week on housework in 2019. For 1880 a fearless assumption is made: suppose that the married-tosingle housework ratio was the same in 1880 as the average ratio between 1965 
and 2019 as computed from the American Heritage Time Use Study and American Time Use Survey. ${ }^{7}$ Consequently, $\mathrm{hrs}_{\mathrm{s}, 1880}=58 \div 2.80$. Thus, the goal for singles is $h_{s, 1880}=20.73 / 112$ and $h_{s, 2020}=6.41 / 112$.

4. Marriage: In 1880 the percentage of never-married women ages 20 to 29 was 38.8 , while by 2019 this number was 76.2 percent. Therefore, ideally $1-m_{1880}=0.388$ and $1-m_{2020}=0.762$.

5. Schooling: The level of schooling is identified as the fraction of the population that was working in white-collar jobs. In 1880 the percentage of the ages 25-to-54 population in white-collar jobs was 16.82. This percentage was 76.54 in 2018 . Hence, the schooling targets are $s_{1880}=0.1682$ and $s_{2020}=0.7654$.

\subsection{Fitting parameter values}

To see if the set of Kuznets facts can be matched, values must be assigned to the model's various parameters. This is done in three ways: First, some parameters are exogenously imposed. Second, other parameters can be backed out from the first-order conditions so that the model hits exactly certain data targets for married households. These first-order conditions provide a theory-based identification strategy for the parameters involved. Additionally, the first-order conditions provide valuable intuition about how the economy will respond to the various forms of technology advancement addressed in Section 6. Third, the remaining parameters are chosen to maximize the fit of the model with respect to some remaining data targets for singles.

\section{Assigning parameter values using direct information}

Begin with the parameters that are exogenously imposed. These fall into 7 broad categories that are discussed now.

1. Prices: Prices for the two periods need to be specified: namely the wage rates, $w_{1880}$ and $w_{2020}$, the college premiums defined as the ratios of the college to noncollege wage rates, $q_{1880} \equiv v_{1880} / u_{1880}$ and $q_{2020} \equiv v_{2020} / u_{2020}$, and the prices of durables, $p_{1880}$ and $p_{2020}$. In the analysis, the wage rate for 1880 is normalized to one; i.e., set $w_{1880}=1$. Over the period in question, wages grew eleven fold, or an average increase of about 1.7 percent per year. Therefore $w_{2020}=11.3 w_{1880}{ }^{8}$ The college premium in 2020 is taken be to $q_{2020}=1.81$. This value corresponds to the income earned from graduating with a four-year college degree relative to the income earned from graduating just from high school-median incomes for males are used, taken from the Census's Current Population Survey in 2018. In the model's steady-state equilibrium, the aggregate real wage, $w$, is related to the

7 This time-use data only goes back as far as 1965 .

8 For the period 1880 to 1988, the real wage data in Williamson (1995) are used, while for 1989 to 2019 real wages are defined to be the real compensation of employees divided by aggregate hours worked as reported in FRED. 
skilled and unskilled wage rates, $v$ and $u$, as follows:

$$
w=s v+(1-s) u .
$$

Therefore, given data on the average wage rate, $w_{2020}$, the college premium, $q_{2020}$, and the level of schooling, $s_{2020}$, values can be backed out for the noncollege and college wage rates:

$$
u_{2020}=\frac{w_{2020}}{s_{2020} q_{2020}+1-s_{2020}} \quad \text { and } \quad v_{2020}=\frac{w_{2020}}{s_{2020}+\left(1-s_{2020}\right) / q_{2020}} .
$$

Little is known about the value of the college premium in $1880, q_{1880}$, so this will be a free parameter in the calibration exercise. A calibrated value for $q_{1880}$ implies values for $u_{1880}$ and $v_{1880}$, given $w_{1880}$ and $s_{1880}$. The price of durables is assumed to fall about 5 percent a year, which is the number used by Greenwood et al. (2016). So, $p_{2020}=1.05^{-(2020-1880)} p_{1880}$. The price for household durables in 1880 is normalized so that $p_{1880}=100$.

2. Household production function: The following values are assigned to the parameters governing household production: $\theta=0.206$ and $\sigma=0.282$. The number for $\theta$ comes from McGrattan et al. (1997). The value for $\sigma$ lies between the numbers in Greenwood et al. (2005b) and McGrattan et al. (1997). A discussion on the selection of $\sigma$ is deferred to Section 6.4. The fact that $\sigma>0$ implies that durables and housework are quite substitutable in household production. Therefore, process innovation in the production of household durables, which lowers their price, will be labor saving. To see this, note that durables, $d$, are chosen to satisfy

$$
\frac{\theta}{1-\theta}\left(\frac{d}{h}\right)^{\sigma-1}=\frac{p}{w} .
$$

This equation states that the marginal rate of substitution of durables for time in household production, as given by the lefthand side, must equal the time price of durable, or the righthand side. The parameter $\sigma$ regulates the response of the durables/housework ratio in the home to a change in the time price of durables. The elasticity of substitution between durables and housework is $-1 /(1-\sigma)$, which in absolute value is increasing in $\sigma$. When $0<\sigma<1$ there will be a larger increase in the durables/housework ratio (or equivalently a decrease in the housework/durables ratio) in response to a drop in the time price relative to a Cobb-Douglas production function $(\sigma=0)$.

3. Coefficient of relative risk aversion: A standard value of 1.25 is chosen for the coefficient of relative risk aversion, $\rho$.

4. Household equivalence scale: The household equivalence scale is set to $\varepsilon=$ 0.667 , in line with the OECD's modified scale. The scale assigns a value of 1 to the first adult in family and a value of 0.5 to second one, which implies $\varepsilon=1 /(1+0.5)$.

5. Basic childcare: The American Time Use Survey and Gershuny and Harms (2016) are used to pin down the time cost of basic childcare. Women spent on average 
4.96 hours per week per child in basic childcare in 2019, 3.93 hours in 1965, and 1.22 in 1920 . The average of these three values is selected for $b$; i.e., set $b=2 \times$ $3.37 / 224=0.030$. Here it is assumed that only women provide basic childcare. The 1965 and 2019 numbers are for all married women with and without children and are taken from the American Heritage Time Use Study and American Time Use Survey. The 1920 number is based on Gershuny and Harms (2016) who report that women spent 35 minutes per day (or 4.08 hours per week) on child and adult care in the 1920s. ${ }^{9}$

6. Educating children: Given data on schooling, $s$, and the time spent educating children by parents, $e$, an estimate can be obtained for $\gamma$. Specifically, $\gamma=e / s$. As a measure of schooling, the fraction of the labor force in white-collar jobs is used. Now, about 77 percent of the labor force was in white-collar jobs in 2020 (so that $s_{2020}=0.77$ ). According to the American Time Use survey, a household spent on average 4.41 hours a week educating a child in 2020, implying $e_{2020}=2 \times(4.41 / 224)$ per household. ${ }^{10}$ Thus, $\gamma_{2020}=2 \times(4.41 / 224) / 0.77$. Between 1960 and 1970, 57 percent of the labor force was in white-collar jobs $\left(s_{1965}=0.57\right)$. Data from the American Heritage Time Use Study suggest that in 1965 the time spent on educational activities per child was 1.31 hours per week. Therefore, $\gamma_{1965}=2 \times(1.31 / 224) / 0.57$. Last, the data in Gershuny and Harms (2016) suggest that 0.24 hours per week was spent educating a child in the 1920 s $\left(e_{1920}=2 \times 0.24 / 224\right) .{ }^{11}$ The fraction of white-collar workers was 33.33 percent (an average between 1920 and 1930, so $s_{1920}=0.33$ ). Therefore, $\gamma_{1920}=2 \times(0.24 / 224) / 0.33$. An average of these three values is taken for $\gamma$. This results in $\gamma=0.026$.

7. Child labor in home production: A child is not as productive as an adult in household production. Wages can be used to gauge the productivity of children vis à vis adults. The evidence suggests that the productivity of a child is much less than that of an adult. For example, anecdotal evidence from Abbott (1908, p. 28) is presented in Table 5.1. Lebergott (1964, pp. 49-50) relates that a ten-year-old in 1798 could earn the equivalent of $\$ 22$ a year working as a farm laborer, as compared with $\$ 96$ for an adult. So, how much housework did children do? To answer this question, suppose that poorer countries today resemble the United States in 1880. Webbink et al. (2012) document children's

\footnotetext{
9 To calculate hours per child, divide this by 2.81, the average of the total fertility rates in 1920 and 1930 . An assumption needs to be made about how to split this time between time spent on basic childcare versus educating children. In the 1965 American Heritage Time Use Study, 84 percent of total care time per child by mothers was for basic care. It is assumed that women allocated their time between basic and educational childcare in the same way in the 1920 s.

10 The number pertains to the time spent on educational and play-related child care (per kid) of married men and women with and without children.

11 The 0.24 hours per week correspond to the total amount of child and adult care provided by women multiplied by the fraction of the time women spent per child on educational child care (16 percent according to the 1965 American Heritage Time Use Study).
} 
Table 5.1 Weekly wages in 1815.

\begin{tabular}{l|l} 
Age & $\mathbf{\$}$ \\
Adult man & 5.00 \\
Adult woman & 2.33 \\
16-year-old boy & 2.00 \\
13-year-old boy & 1.50 \\
12-year-old girl & 1.25 \\
10-year-old boy & 0.83 \\
8-year-old girl & 0.75 \\
\hline
\end{tabular}

housework across low-income countries (mostly African and Asian). The average number of hours worked per week for boys and girls ages 8 to 13 was 6 and 9 hours. For 2020, the findings in Hofferth and Sandberg (2001) for the United States are used. They document that children ages 0 to 12 spent 5.48 hours per week in housework. Hence, $\chi_{1880}=(22 / 96) \times 2 \times(7.5 / 224)=0.015$ and $\chi_{2020}=(22 / 96) \times 2 \times(5.48 / 224)=0.011$.

\section{Identifying parameter values using the first-order conditions-inner loop}

The rest of the parameters are fit with respect to a set of data targets. The calibration procedure here has two loops: inner and outer. The inner loop picks the utility parameters governing a married household's tastes over leisure, $\delta$ and $\lambda$, fertility, $\psi$ and $\kappa$, their children's future wages, $\xi$ and $\zeta$, and home goods, $\beta$ and $\nu$. This is done based on observations for a married household's leisure, fertility, educational choice for children, and housework. When doing this, the parameter values for the weight term on a married household's utility from consumption, $\alpha$, and the 1880 college premium, $q_{1880}$, are taken as given. Note that single and married households' utility functions for consumption, home goods, and leisure share the parameters $\alpha, \rho, \beta, \nu$, and $\lambda$.

The inner loop uses the first-order conditions for the married household to back out parameter values so that the model fits exactly a married household's data targets for leisure, fertility, schooling, and housework. These first-order conditions govern household behavior and provide intuition on how the model works. This will be important in Section 6 for understanding how neutral technological advance, skillbiased technological change, and process innovation in the production of labor-saving household durables affect the economy. The first-order conditions also deliver a theory-based identification strategy for certain parameters. The exponents on the various utility functions, $\lambda, \kappa, \zeta$, and $\nu$, are identified from the observed rates of change in the function's argument. The weights on the utility functions, $\delta, \psi, \xi$, and $\beta$, are selected so that the model fits the data for some particular year.

The outer loop then picks the two remaining parameters, $\alpha$ and $q_{1880}$, to maximize the fit of the model over the time-allocation data targets for singles. The choice of these two parameters influences the determination of the inner loop's parameter 
values. Last, the location and scale parameters governing the Gumbel distribution, a and $\mathrm{d}$, are chosen to meet the targets concerning marriage.

Start now with the inner loop. To begin with, consider the married household's choice for leisure, $l$. The leisure first-order condition can be expressed as

$$
\delta l^{-\lambda}=\alpha \varepsilon^{1-\rho}[\underbrace{w(2-b k-\gamma s k-h-l)-p d}_{=c}]^{-\rho} w .
$$

This efficiency condition sets the marginal benefit from leisure equal to its marginal cost. The lefthand side is utility gain from an extra unit of leisure. The righthand side gives the loss in utility from taking a unit of time away from market work. This results in a loss of wages and hence in consumption of $w$. The loss in utility from a unit reduction in consumption is just the marginal utility of consumption or $\alpha \varepsilon^{1-\rho} c^{-\rho}$.

When evaluated at the data targets, this equation implies

$$
\begin{aligned}
& \left(\frac{l_{2020}}{l_{1880}}\right)^{-\lambda}=\left(\frac{c_{2020}}{c_{1880}}\right)^{-\rho} \frac{w_{2020}}{w_{1880}} \\
& =\left[\frac{w_{2020}\left(2-b k_{2020}-\gamma s_{2020} k_{2020}-h_{2020}-l_{2020}\right)-p_{2020} d_{2020}}{w_{1880}\left(2-b k_{1880}-\gamma s_{1880} k_{1880}-h_{1880}-l_{1880}\right)-p_{1880} d_{1880}}\right]^{-\rho} \frac{w_{2020}}{w_{1880}} .
\end{aligned}
$$

It is clear that the change in leisure, $l_{2020} / l_{1880}$, which is connected to shifts in consumption, $c_{2020} / c_{1880}$, and wages, $w_{2020} / w_{1880}$, is governed by the exponent on the utility function for leisure, $\lambda$. Think about the movements in consumption and wages as representing income and substitution effects, respectively. As consumption rises the household would like more leisure, ceterus paribus, because it induces a decline in the marginal utility of leisure or the benefit from working. Growth in wages, other things equal, causes leisure to fall since this raises the benefit from working when consumption is held fixed. Without further information, it is unclear whether leisure should rise or fall in a growing economy; this will be returned to in Section $6 .{ }^{12}$

Conditional on values for the variables on the righthand side, $\lambda$ can be selected to match the desired change in leisure. ${ }^{13}$ The solution for $\lambda$ is dependent on the value for $\rho$ that is set exogenously based on direct information. Once $\lambda$ is determined, the weight on the leisure utility function of married households, $\delta$, can be obtained by using the first-order condition for leisure to hit the leisure target for 2020 or to solve the equation

$$
\begin{aligned}
\delta l_{2020}^{-\lambda}=\alpha \varepsilon^{1-\rho}\left[w_{2020}\left(2-b k_{2020}-\gamma s_{2020} k_{2020}-h_{2020}-l_{2020}\right)\right. & \\
& \left.-p_{2020} d_{2020}\right]^{-\rho} w_{2020}
\end{aligned}
$$

\footnotetext{
12 Note that shifts in the costs of children or durables will also affect leisure over time via an income effect operating through consumption.

13 By taking logs of the above equation an explicit solution for $\lambda$ in terms of the other variables obtains.
} 
Next, move onto fertility, $k$, which has the efficiency condition

$$
\psi k^{-\kappa}=\delta l^{-\lambda}(b+\gamma s-\chi) .
$$

The lefthand side is the marginal utility of a child. The righthand side is the marginal cost in terms of the forgone leisure. An extra child costs $b$ units of time in terms of basic childcare and $\gamma s$ in time spent on education. This time cost is offset by the effective time the child spends in home production, $\chi$. The net time cost is multiplied by marginal utility of leisure.

From first-order condition (5.4), it transpires that

$$
\left(\frac{k_{2020}}{k_{1880}}\right)^{-\kappa}=\left(\frac{l_{2020}}{l_{1880}}\right)^{-\lambda} \frac{b+\gamma s_{2020}-\chi_{2020}}{b+\gamma s_{1880}-\chi_{1880}} .
$$

As can be seen, $\kappa$ is central for controlling the change in fertility, $k_{2020} / k_{1880}$, associated with shifts in leisure, $l_{2020} / l_{1880}$, and the cost of having children, $\left(b+\gamma s_{2020}-\right.$ $\left.\chi_{2020}\right) /\left(b+\gamma s_{1880}-\chi_{1880}\right)$. A rise in leisure will be linked with an increase in the number of kids, while a jump in the cost of kids is associated with a decrease in fertility. Since in the US data household leisure rises, the cost of a child must have risen in order to see a decline in fertility. This happens when there is an ascent in schooling. This will be the prime driver of the fall in fertility, as will be seen in Section 6. The exponent $\kappa$ can be selected to match the targeted decline in fertility. ${ }^{14}$ The constant term on the utility function for fertility is chosen so that the following equation is met

$$
\psi k_{2020}^{-\kappa}=\delta l_{2020}^{-\lambda}\left[b+\gamma s_{2020}-\chi_{2020}\right]
$$

Turn to schooling, $s$. The first-order condition for schooling can be written as

$$
\xi[s v+(1-s) u]^{-\zeta}(v-u)=\delta l^{-\lambda} \gamma k .
$$

The lefthand side gives the benefit to parents from investing in an extra unit of education for their children. This increases the adult child's wages by $v-u$, where the marginal utility to the parents of an extra unit of earnings is $\xi[s v+(1-s) u]^{-\zeta}$. The righthand side is the cost from an extra unit of schooling. The time cost of the extra unit of education for $k$ kids is $\gamma k$, which could have been used for leisure. The marginal utility of leisure is $\delta l^{-\lambda}$. In this equation $w=s v+(1-s) u$ is the average wage in the economy, while $v-u$ can be thought of as representing the college premium. So, Eq. (5.5) can be equivalently expressed in terms of the average wage, $w$, and the college premium, $q=v / u .^{15}$

\footnotetext{
$\overline{14}$ Again, by taking logs of the above equation an explicit solution for $\kappa$ results in terms of the other variables.

15 Specifically, it is easy to calculate that $v-u=w(q-1) /(s q+1-s)$.
} 
When (5.5) holds at the data targets,

$$
\left[\frac{s_{2020} v_{2020}+\left(1-s_{2020}\right) u_{2020}}{s_{1880} v_{1880}+\left(1-s_{1880}\right) u_{1880}}\right]^{-\zeta} \frac{v_{2020}-u_{2020}}{v_{1880}-u_{1880}}=\left(\frac{l_{2020}}{l_{1880}}\right)^{-\lambda} \frac{k_{2020}}{k_{1880}} .
$$

Contingent upon a value for $\lambda$, it's clear that $\zeta$, or the exponent in the utility function for a child's future wage, regulates the change in schooling over time. By eyeballing this equation, it is easy to deduce that as the college premium climbs, as measured by $\left(v_{2020}-u_{2020}\right) /\left(v_{1880}-u_{1880}\right)$, schooling will move upwards. The hike in the college premium will be the key factor for explaining the upswing in schooling in Section 6. From the preceding analysis of (5.4), more schooling implies fewer kids, which will reinforce the rise in schooling. On this, note that a decline in fertility, $k_{2020} / k_{1880}<1$, and also a growth in leisure, $l_{2020} / l_{1880}>1$, will be connected with more schooling because its cost has fallen. The value of $\zeta$ that solves the above equation is chosen. Recall that the college premium for $1880, q_{1880}$, is determined in the outer loop. This implies a value for $v_{1880}-u_{1880}$. The weight term in the utility function for a child's future wage, $\xi$, can be nailed down from

$$
\xi\left[s_{2020} v_{2020}+\left(1-s_{2020}\right) u_{2020}\right]^{-\zeta}\left(v_{2020}-u_{2020}\right)=\delta l_{2020}^{-\lambda} \gamma k_{2020},
$$

when assuming values for $\lambda, \delta$, and $\zeta$.

Finally, the first-order condition for a married household's housework, $h$, reads

$$
\beta \varepsilon^{1-\rho}(1-\theta)\left[\theta d^{\sigma}+(1-\theta)(h+\chi k)^{\sigma}\right]^{(1-\nu-\sigma) / \sigma}(h+\chi k)^{\sigma-1}=\delta l^{-\lambda} .
$$

The lefthand side gives the benefit of an extra unit of labor in the home, while the righthand side is the cost in terms of forgone leisure. It should be apparent by now that the exponent on the utility term for home goods, $v$, can be tied down by the change in nonmarket goods,

$$
\begin{aligned}
& {\left[\frac{n_{2020}}{n_{1880}}\right]^{(1-\nu-\sigma)}\left[\frac{h_{1880}+\chi_{1880} k_{1880}}{h_{2020}+\chi_{2020} k_{2020}}\right]^{\sigma-1}=} \\
& {\left[\frac{\theta d_{2020}^{\sigma}+(1-\theta)\left(h_{2020}+\chi_{2020} k_{2020}\right)^{\sigma}}{\theta d_{1880}^{\sigma}+(1-\theta)\left(h_{1880}+\chi_{1880} k_{1880}\right)^{\sigma}}\right]^{(1-\nu-\sigma) / \sigma}\left[\frac{h_{1880}+\chi_{1880} k_{1880}}{h_{2020}+\chi_{2020} k_{2020}}\right]^{\sigma-1}=} \\
& \left(\frac{l_{2020}}{l_{1880}}\right)^{-\lambda} .
\end{aligned}
$$

From this equation it can be seen that a boost in the input of household durables will reduce housework, ceterus paribus, when $1-v-\sigma<0$. This transpires because more durables lead to a drop in the marginal value of housework for generating utility from nonmarket goods. This effect will be bigger the larger $v$ and $\sigma$ are. The bigger $v$ is, the less valuable is an extra unit of home goods. The larger $\sigma$ is, the more substitutable capital and labor are in the home. A fall in the price of household durables will result in more durables being used in home. This mechanism will be important in Section 6 
for explaining the fall in housework. Since the need to use labor in the home provides a motive for marriage, this will also cause a waning in marriage. Finally, the constant term $\beta$ can be determined by fitting the equation to some baseline year, specifically 1880 , so that

$$
\begin{aligned}
\beta \varepsilon^{1-\rho}(1-\theta)\left[\theta d_{1880}^{\sigma}+(1-\theta)\left(h_{1880}+\right.\right. & \left.\left.\chi_{1880} k_{1880}\right)^{\sigma}\right]^{(1-v-\sigma) / \sigma} \\
& \times\left(h_{1880}+\chi_{1880} k_{1880}\right)^{\sigma-1}=\delta l_{1880}^{-\lambda} .
\end{aligned}
$$

\section{Calibrating parameter values to maximize model fit-outer loop}

Turn now to the outer loop. The inner loop matches exactly the married household's data targets for fertility, schooling, housework, and market hours (hence leisure). The outer loop helps the model match the targets for single households, particularly their housework and market hours. The parameters $\alpha$ and $q_{1880}$ are selected to get the best fit possible for the model's predictions about singles. Specifically, denote the $i$ 'th data target by $\mathbf{D}_{i}$ and the model's solution for this target by $\mathbf{M}_{i}\left(\alpha, q_{1880}\right)$. The parameters $\alpha$ and $q_{1880}$ solve

$$
\min _{\alpha, q_{1880}} \sum_{i}\left[\frac{\mathbf{D}_{i}-\mathbf{M}_{i}\left(\alpha, q_{1880}\right)}{\mathbf{D}_{i}}\right]^{2},
$$

where each observation for singles is weighted uniformly. This minimization routine takes into account how the choice of $\alpha$ and $q_{1880}$ affects $\delta, \lambda, \psi, \kappa, \xi, \zeta, \beta$, and $\nu$ as described above.

Finally, to match the marriage facts, recall that the maximization problems (4.2) and (4.4) give values for single and married lives, $S$ and $M$. Now, using Eq. (4.5), for the fraction of the population that is unmarried, $1-\mathrm{m}$, it follows that

$$
\ln [-\ln (1-\mathrm{m})]=-(S-M-\mathrm{a}) / \mathrm{d} .
$$

If the above equation holds at the data targets, then

$$
\frac{\ln \left[-\ln \left(1-\mathrm{m}_{2020}\right)\right]}{\ln \left[-\ln \left(1-\mathrm{m}_{1880}\right)\right]}=\frac{S_{2020}-M_{2020}-\mathrm{a}}{S_{1880}-M_{1880}-\mathrm{a}} .
$$

So, the location parameter for the Gumbel distribution, a, can be selected to hit the change in the fraction of the population that is single. The distribution function for joy, $j$, regulates the outflow from marriage in response to hikes in the relative value of single life or the threshold value for joy, $S-M=j^{*}$. The location parameter regulates this response. Given a, the scale parameter, $d$, can be used to match the fraction of the population that is single in 2020 by employing the equation

$$
\mathrm{d}=-\frac{S_{2020}-M_{2020}-\mathrm{a}}{\ln \left[-\ln \left(1-\mathrm{m}_{2020}\right)\right]}
$$

Values for the location and scale parameters are chosen after values for all the other parameters have been selected. The procedure here is akin to the matching strategy employed in the inner loop. 
Table 5.2 Parameter values.

\begin{tabular}{|c|c|c|c|}
\hline Parameter & Description & Value & Identification \\
\hline \multicolumn{4}{|c|}{ Market consumption } \\
\hline$\alpha, \rho$ & Weight, exponent & $0.154,1.250$ & Eq. (5.7), literature \\
\hline \multicolumn{4}{|c|}{ Home goods consumption } \\
\hline$\beta, v$ & Weight, exponent & $0.059,1.708$ & Eq. (5.6) \\
\hline \multicolumn{4}{|l|}{ Leisure } \\
\hline$\delta$ & Weight, married & 0.283 & Eq. (5.3) \\
\hline $1-\alpha-\beta$ & Weight, single & 0.787 & Implied \\
\hline$\lambda$ & Exponent & 0.407 & Eq. (5.3) \\
\hline \multicolumn{4}{|l|}{ Fertility } \\
\hline$\psi, \kappa$ & Weight, exponent & $0.014,0.541$ & Eq. (5.4) \\
\hline \multicolumn{4}{|l|}{ Schooling } \\
\hline$\xi, \zeta$ & Weight, exponent & $0.099,1.607$ & Eq. (5.5) \\
\hline \multicolumn{4}{|c|}{ Home production technology } \\
\hline $\begin{array}{c}\theta, \sigma \\
\chi_{1880}, \chi_{2020}\end{array}$ & $\begin{array}{l}\text { Durables weight, exponent } \\
\text { Child labor-productivity: } \\
1880,2020\end{array}$ & $\begin{array}{l}0.206,0.282 \\
0.015,0.011\end{array}$ & $\begin{array}{c}\text { Literature, Sec } 6.4 \\
\text { Data }\end{array}$ \\
\hline \multicolumn{4}{|l|}{ Cost of Children } \\
\hline$b, \gamma$ & basic, education & $0.030,0.026$ & Data \\
\hline \multicolumn{4}{|l|}{ Marriage, Gumbel } \\
\hline$a, d$ & location, shape & $-0.593,0.028$ & Eqs. (5.8) and (5.9) \\
\hline \multicolumn{4}{|c|}{ Prices (continuous growth rates are presented) } \\
\hline$p_{1800}, p_{2020}, \% \Delta p$ & $\begin{array}{l}\text { Durables: } 1880 \text { and } 2020 \\
\text { levels, growth }\end{array}$ & $100.000,0.108,-4.879 \%$ & Normalization, literature \\
\hline$w_{1800}, w_{2020}, \% \Delta w$ & $\begin{array}{l}\text { Wages: } 1880 \text { and } 2020 \\
\text { levels, growth }\end{array}$ & $1.000,11.300,1.732 \%$ & Normalization, data for $\% \Delta$ \\
\hline$q_{1880}, q_{2020}, \% \Delta q$ & $\begin{array}{l}\text { Skill premium: } 1880 \text { and } \\
2020 \text { levels, growth }\end{array}$ & $1.384,1.810,0.192 \%$ & Eq. (5.7), 2020 Data \\
\hline \multicolumn{4}{|l|}{ Equivalence scale } \\
\hline$\varepsilon$ & Equivalence scale & 0.667 & OECD \\
\hline
\end{tabular}

\subsection{Results}

The parameter values resulting from the calibration procedure are displayed in Table 5.2. Table 5.3 presents the match between the data and model. The results show a close match between the data and model. The above calibration procedure ensures that for a married household the model will exactly match the stylized facts for time allocations, fertility, and schooling. It also guarantees that the model's fit for the marriage statistics is perfect. The framework also captures the fact that over time singles do less housework, cut back on their market work, and enjoy more leisure. While the trends are correct, the levels for these three variables are off a bit for singles.

Last, Reid (1934) noted in her time that the value of housework had been overlooked. She said (1934, p. v):

The household is our most important economic institution. Yet economics of household production is a neglected field of study. With few exceptions the interest of economists has been concentrated on that part of our economic system which is organized on a price basis. The productive work of the household has been overlooked, even though more workers are engaged in it than any other single industry. 
Table 5.3 Results, data and model.

\begin{tabular}{|c|c|c|c|}
\hline Variable & Description & $\begin{array}{c}\text { Data } \\
1880,2020\end{array}$ & $\begin{array}{c}\text { Model } \\
1880,2020\end{array}$ \\
\hline \multicolumn{4}{|l|}{ Fertility } \\
\hline$k$ & Fertility rate & $4.240,1.640$ & $4.240,1.640$ \\
\hline \multicolumn{4}{|c|}{ Schooling } \\
\hline$s$ & Schooling & $0.168,0.765$ & $0.168,0.765$ \\
\hline \multicolumn{4}{|l|}{ Time } \\
\hline \multirow[t]{2}{*}{$h$} & Housework (married) & $0.518,0.156$ & $0.518,0.156$ \\
\hline & Housework (single) & $0.185,0.057$ & $0.251,0.072$ \\
\hline \multirow[t]{2}{*}{$t$} & Market work (married) & $0.614,0.597$ & $0.614,0.597$ \\
\hline & Market work (single) & $0.360,0.302$ & $0.226,0.218$ \\
\hline \multirow[t]{2}{*}{$l$} & Leisure (married), implied & $0.722,1.165$ & $0.722,1.165$ \\
\hline & Leisure (single), implied & $0.455,0.641$ & $0.523,0.710$ \\
\hline$b k$ & Childcare & $0.128,0.049$ & $0.128,0.049$ \\
\hline$e k$ & Educational care & $0.019,0.033$ & $0.019,0.033$ \\
\hline \multicolumn{4}{|c|}{ Marriage } \\
\hline$m$ & Fraction married & $0.612,0.238$ & $0.612,0.238$ \\
\hline $1-m$ & Fraction single (unmarried) & $0.388,0.762$ & $0.388,0.762$ \\
\hline
\end{tabular}

This has a ring of truth today, too. As an aside, some measures of the value of household production are presented in Table 5.4. A traditional measure of household production's worth is just to multiply the labor used in the home by the wage rate and divide this through by GDP, or here just expenditure on market consumption and durables. By this measure, in 1880 the aggregate value of household production was roughly the same as market expenditure. ${ }^{16}$ Interestingly, it is larger for single households than for married ones. This transpires because married households can afford to devote more time to market work. By 2020 the value of household-sector output had fallen markedly relative to market expenditure (to about one-third of its 1880 value). An alternative measure of household production's value is to multiply the output of the home sector by its implicit relative price, or the marginal rate of substitution of home goods for market goods. This again is divided through by market expenditure. Now, between 1880 and 2020, the value of household production does not fall by nearly as much. This occurs because the relative price of home goods rises over this period, as market consumption has grown much more than nonmarket consumption, causing the decline in the marginal utility of market consumption to be stronger than the decline in the marginal utility of nonmarket consumption. This can be seen by measuring the value of home goods in 2020 using 1880 prices as a base year. The decline in the household sector is greater now and looks similar to the wage-based measure.

\footnotetext{
16 The aggregate measure is just a population weighted sum of the married and single measures.
} 
Table 5.4 Value of household production.

\begin{tabular}{l|c|c}
$\begin{array}{l}\text { Description } \\
\text { (all relative to household expenditure) }\end{array}$ & $\mathbf{1 8 8 0}$ & $\mathbf{2 0 2 0}$ \\
\hline \multicolumn{3}{|c}{ Wage Based } \\
\hline Aggregate & 0.98 & 0.31 \\
Married & 0.95 & 0.29 \\
Single & 1.11 & 0.33 \\
\hline \multicolumn{3}{|c}{ Price Based } \\
\hline Aggregate & 1.00 & 0.61 \\
Married & 0.97 & 0.57 \\
Single & 1.14 & 0.64 \\
\hline \multicolumn{1}{c}{ Price Based-1880 base year } \\
\hline Aggregate & 1.00 & 0.28 \\
Married & 0.97 & 0.26 \\
Single & 1.14 & 0.29 \\
\hline
\end{tabular}

\section{Propelling the great transition}

Direct attention now to the driving forces behind the great transition. These are the growth in the general level of wages, $w$, the fall in the price of household durables, $p$, and the rise in the college premium, $q$. The driving forces underlying these endogenous shifts in prices are various forms of technological progress: viz, neutral technological advance, skill-biased technological change, and process innovation in the production of labor-saving household durables. These three underlying exogenous forces are examined in turn, which serve to illustrate the mechanisms at work. By tacking on a production sector in the manner shown below, the baseline equilibria for 1880 and 2020 are retained untouched. The general equilibrium analysis kicks in when perturbations from the baseline 2020 equilibrium are studied.

There are other significant technological changes left aside by the current analysis. Improvements in contraception is an important one. Goldin and Katz (2002) highlight how better contraception, the pill, allowed women to take professional careers and, at the same time, delay their entry into marriage. ${ }^{17}$ Another fundamental change in the US has been the decline of agriculture and the ascent of manufacturing followed by a fall in manufacturing and a jump in services. This trend favored brain over the brawn and eroded the comparative advantage of men in workplace. Galor and Weil (1996) model how this process encouraged women's entry into the labor force and narrowed the gender wage gap. ${ }^{18}$ Another significant change over the last

\footnotetext{
17 The impact of contraceptive technology on premarital sex and entry into marriage is studied by Greenwood et al. (2021), who also provide a literature review.

18 For further explorations of this idea within quantitative macro models, see Ngai and Petrongolo (2017) and Rendall (2018).
} 
century is the rise of life expectancy, which some have argued is an important factor driving the increase in schooling.

To model the great transition, a production sector is appended onto the framework. To this end, suppose that output, $\mathbf{o}$, is produced according to a CES production function using unskilled and skilled labor, $\mathbf{u}$ and $\mathbf{v}$ :

$$
\mathbf{o}=\mathbf{z}\left[(1-\omega) \mathbf{u}^{\iota}+\omega \mathbf{x} \mathbf{v}^{\iota}\right]^{1 / \iota}, \text { with } \iota \leq 1
$$

Here increases in $\mathbf{z}$ reflect neutral technological progress while shifts in $\mathbf{x}$ govern skill-biased technological change. Labor-saving household durables are produced according to a linear production function where one unit of final output produces $1 / p$ units of durable goods. Thus, upward movements in $1 / p$, or equivalently drops in $p$, stand in for process innovation in the production of household durables.

A firm hires unskilled and skilled labor to maximize its profits or to solve the problem

$$
\max _{\mathbf{u}, \mathbf{v}}\left\{\mathbf{z}\left[(1-\omega) \mathbf{u}^{\iota}+\omega \mathbf{x} \mathbf{v}^{\iota}\right]^{1 / \iota}-u \mathbf{u}-v \mathbf{v}\right\} .
$$

The first-order conditions from this problem state that the marginal products of unskilled and skilled labor equal the wages rates, $u$ and $v$, for the two types of labor. Thus,

$$
\mathbf{z}\left[(1-\omega) \mathbf{u}^{\iota}+\omega \mathbf{x v}^{\iota}\right]^{1 / \iota-1}(1-\omega) \mathbf{u}^{\ell-1}=u
$$

and

$$
\mathbf{z}\left[(1-\omega) \mathbf{u}^{\iota}+\omega \mathbf{x} \mathbf{v}^{\iota}\right]^{1 / \iota-1} \omega \mathbf{x v}^{\iota-1}=v .
$$

The college premium, $q=v / u$, then reads

$$
\frac{v}{u}=\frac{\omega \mathbf{x}}{1-\omega}\left(\frac{\mathbf{v}}{\mathbf{u}}\right)^{\iota-1}
$$

So the college premium is a function of the skill-biased technology shift factor, $\mathbf{x}$, and the aggregate supplies of unskilled and skilled labors, $\mathbf{u}$ and $\mathbf{v}$. It is not a function of the neutral technology shift factor, $\mathbf{z}$. Next, aggregate market hours worked, $\mathbf{t}$, is

$$
\mathbf{t}=m t_{m}+(1-m) t_{s}
$$

where $m$ is the fraction of households that are married, $t_{m}$ is market hours worked by a married household, and $t_{s}$ is hours worked by a single one. Accordingly, aggregate hours of unskilled and skilled labor, $\mathbf{u}$ and $\mathbf{v}$, are

$$
\mathbf{u}=(1-s) \mathbf{t}
$$

and

$$
\mathbf{v}=s \mathbf{t}
$$


These two relationships allow the college premium to be rewritten as

$$
\frac{v}{u}=\frac{\omega \mathbf{x}}{1-\omega}\left(\frac{s}{1-s}\right)^{\iota-1} .
$$

To proceed estimates are needed for the skill-biased and neutral technology factors, $\mathbf{x}$ and $\mathbf{z}$. From the above equation, it is apparent that

$$
\frac{v_{2020} / u_{2020}}{v_{1880} / u_{1880}}=\frac{\mathbf{x}_{2020}}{\mathbf{x}_{1880}}\left[\frac{s_{2020} /\left(1-s_{2020}\right)}{s_{1880} /\left(1-s_{1880}\right)}\right]^{l-1} .
$$

From the baseline simulation, values are known for $m, s, t_{m}, t_{s}, u$, and $v$ for 1880 and 2020. This implies that values for $\mathbf{t}$ are also known for these two years. Given numbers for $\omega$ and $\iota$, the change in the college premium can be used to calibrate skill-biased technological change or $\mathbf{x}_{2020} / \mathbf{x}_{1880}$. Then, by using the college premium for one year, a value for $\mathbf{x}$ for that year can be assigned from (6.2). Last, $\mathbf{z}_{1880}$ and $\mathbf{z}_{2020}$ can be backed out by using (6.1). To do this, values for $\iota$ and $\omega$ are needed to implement the procedure. Acemoglu and Autor (2011, Table 8) estimate the elasticity of substitution between skilled and unskilled labor for the 1963-2008 period. Their estimates suggest that $\iota$ lies in the range [0.444, 0.661]. A value of 0.552 , the average of their estimates, is selected here. This implies an elasticity of substitution between skilled and unskilled labor of $-2.23 .{ }^{19}$ Additionally, from the constant terms in their regressions, a range of values for $\omega$ can be recovered. The average value of 0.439 is selected.

The upshot of the above procedure is presented in Table 6.1. The rise in $\mathbf{x}$ can be thought of as reflecting a shift from brawn to brain as mechanization reduced the need for physical labor. Neutral technological progress, skill-biased technological change, and process innovation in the production of labor-saving household durables are now each switched off in isolation. The results are shown in Table 6.2 (columns 3, 4, and 5), together with the US data (column 1) and the results for the baseline calibration (column 2).

\subsection{Neutral technological progress, $\mathbf{z}$}

Neutral technological progress is shut down in the first experiment. To do this, let $\Delta \mathbf{z}=0$ so that $\mathbf{z}_{2020}=\mathbf{z}_{1880}$, while keeping $\mathbf{x}$ and $p$ at the values specified in the baseline calibration. Thus, $\Delta \mathbf{x}>0$ and $\Delta p<0$. The college premium, $q=v / u$, can still change due to shifts in factor supplies. The results of this experiment are reported in column 3 of Table 6.2. The salient feature of this experiment is that things don't change dramatically from the baseline 2020 calibration (column 2), except for living standards. Households are much poorer in 2020 relative to the baseline calibration,

\footnotetext{
19 In interesting work, Bils et al. (2020) allow firms to choose their production function depending upon the wages for skilled and unskilled labor. They find that this results in a higher elasticity of substitution between the two types of labor.
} 
422 CHAPTER 7 The great transition: Kuznets facts for family-economists

Table 6.1 Technology parameter values.

\begin{tabular}{|c|c|c|c|}
\hline Parameter & Description & Value & Identification \\
\hline \multicolumn{4}{|c|}{ Market Production Function } \\
\hline$\omega, \iota$ & Weight on skilled labor, exponent & $0.439,0.552$ & Literature \\
\hline \multicolumn{4}{|c|}{ Technology Factors (continuous growth rates are presented) } \\
\hline $\mathbf{x}_{1880}, \mathbf{x}_{2020}, \% \Delta \mathbf{x}$ & $\begin{array}{l}\text { Skill biased: } 1880 \text { and } 2020 \\
\text { levels, growth }\end{array}$ & $0.864,3.920,1.081 \%$ & Eq. (6.2) \\
\hline $\mathbf{z}_{1880}, \mathbf{z}_{2020}, \% \Delta \mathbf{z}$ & $\begin{array}{l}\text { Neutral: } 1880 \text { and } 2020 \text { levels, } \\
\text { growth }\end{array}$ & $2.192,4.157,0.457 \%$ & Eq. (6.1) \\
\hline$p_{1880}, p_{2020}, \% \Delta p$ & $\begin{array}{l}\text { Process Innovation: } 1880 \text { and } \\
2020 \text { levels, growth }\end{array}$ & $100.000,0.108,-4.879 \%$ & Literature \\
\hline
\end{tabular}

Table 6.2 Results, experiments.

\begin{tabular}{|c|c|c|c|c|c|c|c|}
\hline \multirow[t]{3}{*}{ Variable } & \multirow[t]{3}{*}{ Description } & \multirow{3}{*}{$\begin{array}{c}\text { Data } \\
1 \\
1880,2020\end{array}$} & \multirow{2}{*}{\multicolumn{2}{|c|}{\begin{tabular}{|c} 
Baseline Model \\
2
\end{tabular}}} & \multirow{3}{*}{\begin{tabular}{|c|} 
Fixed z \\
3 \\
2020 \\
\end{tabular}} & \multirow{3}{*}{\begin{tabular}{|c|} 
Fixed $x$ \\
4 \\
2020 \\
\end{tabular}} & \multirow{3}{*}{$\begin{array}{c}\text { Fixed } p \\
5 \\
2020\end{array}$} \\
\hline & & & & & & & \\
\hline & & & 1880 & 2020 & & & \\
\hline \multicolumn{8}{|l|}{ Fertility } \\
\hline$k$ & Fertility rate & $4.240,1.640$ & 4.240 & 1.640 & 1.408 & 3.616 & 1.352 \\
\hline \multicolumn{8}{|c|}{ Schooling } \\
\hline$s$ & Schooling & $0.168,0.765$ & 0.168 & 0.765 & 0.850 & 0.156 & 0.788 \\
\hline \multicolumn{8}{|l|}{ Time } \\
\hline \multirow[t]{2}{*}{$h$} & Housework (married) & $0.518,0.156$ & 0.518 & 0.156 & 0.199 & 0.253 & 0.558 \\
\hline & Housework (single) & $0.185,0.057$ & 0.251 & 0.072 & 0.089 & 0.124 & 0.240 \\
\hline \multirow[t]{2}{*}{$t$} & Market work (married) & $0.614,0.597$ & 0.614 & 0.597 & 0.638 & 0.709 & 0.438 \\
\hline & Market work (single) & $0.360,0.302$ & 0.226 & 0.218 & 0.233 & 0.262 & 0.157 \\
\hline \multirow[t]{2}{*}{$l$} & Leisure (married) & $0.722,1.165$ & 0.722 & 1.165 & 1.090 & 0.914 & 0.935 \\
\hline & Leisure (single) & $0.455,0.641$ & 0.523 & 0.710 & 0.678 & 0.613 & 0.603 \\
\hline$b k$ & Childcare & $0.128,0.049$ & 0.128 & 0.049 & 0.042 & 0.109 & 0.041 \\
\hline$e k$ & Educational care & $0.019,0.033$ & 0.019 & $\mathbf{0 . 0 3 3}$ & 0.031 & 0.015 & 0.028 \\
\hline \multicolumn{8}{|c|}{ Marriage } \\
\hline$m$ & Fraction married & $0.612,0.238$ & 0.612 & 0.238 & 0.286 & 0.326 & 0.986 \\
\hline $1-m$ & Fraction single (unmarried) & $0.388,0.762$ & 0.388 & 0.762 & 0.714 & 0.674 & 0.014 \\
\hline \multicolumn{8}{|l|}{ Prices } \\
\hline$w$ & Average wage & & 1.000 & 11.300 & 6.170 & 1.887 & 11.424 \\
\hline$q$ & College premium, $v / u$ & & 1.384 & 1.810 & 1.413 & 1.439 & 1.706 \\
\hline \multicolumn{8}{|l|}{ Goods } \\
\hline \multirow[t]{2}{*}{$c$} & Market goods (married) & & 0.600 & 4.878 & 2.942 & 1.077 & 4.582 \\
\hline & Market goods (single) & & 0.220 & 1.691 & 1.026 & 0.385 & 1.617 \\
\hline \multirow[t]{2}{*}{$d$} & Stock of durables (married) & & 0.000 & 17.337 & 9.186 & 2.416 & 0.004 \\
\hline & Stock of durables (single) & & 0.000 & 7.161 & 3.812 & 1.021 & 0.002 \\
\hline \multirow[t]{2}{*}{$n$} & Home goods (married) & & 0.281 & 0.821 & 0.687 & 0.509 & 0.316 \\
\hline & Home goods (single) & & 0.121 & 0.339 & 0.285 & 0.215 & 0.132 \\
\hline
\end{tabular}


a fact reflected by the lower average real wage, $w$, in 2020. This causes a large drop in market consumption, $c$, for both married and single households. As a consequence the marginal benefit from working in the market moves up due to an income effect, as can be gleaned from the righthand side of (5.3). The substitution effect works in the opposite direction, so the net positive effect is rather weak. All households work more as a result so that $t$ rises. Additionally, households purchase a smaller quantity of durables, $d$. This leads to a drop in the consumption of home goods, $n$, which motivates an increase in housework, $h$; the marginal benefit of housework or the lefthand side of (5.6) rises. To compensate for the extra time spent on housework and in the market, households cut back on leisure, $l$. Leisure is still considerably higher than its 1880 value because the stock of labor-saving durables is still much larger than in 1880.

For married households the drop in leisure raises the marginal cost of children relative to the 2020 baseline-the righthand side of (5.4). This induces a drop in fertility, $k$, compared with the baseline 2020 calibration. The drop in fertility from 1880 is more pronounced now. Consequently, time spent on basic childcare, $b k$, is smaller now. Since married households are having fewer kids, it pays to educate them more so $s$ rises-the righthand side of (5.5) falls. That is, there is a substitution away from the quantity of children toward the quality of children. Still, due to the drop in fertility, time spent on educating kids, $e k$, falls from the baseline. The college premium, $q=v / u$, comes down as a result of the increase in the level of skill.

Last, the benefit of marriage is larger relative to the 2020 baseline calibration as a result of the declines in home goods, market goods, and leisure. So, $m$ rises and $s$ falls. Hence, the drop in marriage from 1880 is smaller than in the 2020 baseline. The impact on marriage relative to the 2020 baseline is relatively small because on the one hand, people are poorer, which is reflected in less consumption and leisure. This promotes marriage. On the other hand, married couples have fewer kids, and this raises the value of single life vis à vis married life. Overall, by comparing the results of this exercise with the baseline calibration, it is apparent in this setup that neutral technological progress is not the primary driver of the rise in leisure, the drop in fertility, the increase in educational attainment, and the waning in marriage. It is an important force, however, in the rise of living standards.

\subsection{Skill-biased technological change, $\mathbf{x}$}

Skill-biased technological progress is unplugged in the second experiment so that $\Delta \mathbf{x}=0$ (i.e., $\mathbf{x}_{2020}=\mathbf{x}_{1880}$ ). Neutral technological progress and the price of durables behave as in the baseline model; i.e., $\Delta \mathbf{z}>0$ and $\Delta p<0$. The major change here compared with the 2020 baseline calibration (column 2) is that fertility, $k$, is much higher, and the fraction of the population that is schooled, $s$, is significantly lowersee column 4 of Table 6.2. When skill-biased technological change is turned off, the reward from educating a child in 2020 drops-the lefthand side of (5.5) falls because the college premium is lower. The freed-up time from schooling kids goes into having more of them; i.e., the cost of having children falls as the righthand side of Eq. (5.4) 
shows. As in the previous experiment, households are much poorer now so they consume less, work more, reduce spending on durables, do more housework, and have less leisure. The benefit of marriage rises relative to the 2020 baseline model. The fact that people are poorer once again encourages marriage. Fertility is higher but this positive effect on marriage is offset by a decline in children's educational attainment. By comparing the results of this experiment with the baseline calibration, the upshot is that skill-biased technological progress is an important driver of the decline in fertility and the rise in educational attainment. Other than a large fall in living standards, the effect on the other variables is more moderate.

\subsection{The fall in the price of household durables, $p$}

To execute the third experiment, process innovation in the production of labor-saving household durables is turned off so that $\Delta p=0$, implying $p_{2020}=p_{1880}$. The other technology drivers, $\mathbf{z}$ and $\mathbf{x}$, operate as in the baseline model; that is, $\Delta \mathbf{x}>0$ and $\Delta \mathbf{z}>0$. Again, wages, $u, v$, and $w$, may react in response to movements in labor supplies. The main takeaway from this experiment is that the drop in the price of labor-saving household durables is important for explaining the decline in housework and the waning in marriage-Table 6.2, column 5. Household durables are now much more expensive, so people purchase less of them. This raises the benefit of working at home as shown on the lefthand side of (5.6). As a consequence of the need to devote more time to housework, time in 2020 is scarcer. There is a large drop in market work, $t$, relative to the 2020 baseline, as well as a noticeable decline in leisure, $l$. The scarcity of time also encourages a switch toward having fewer, but better educated, kids. The benefit of marriage increases because the difference in the utilities between marrieds and singles, deriving from leisure and the consumption of home goods, widens. As a result the fraction of households that decide to marry rises considerably-even higher than in 1880 due to the boost in utility from having better educated children.

\subsection{The great transition's transitions}

The above results can be made even sharper by examining some quasitransitional dynamics for the model. Suppose that $\mathbf{z}, \mathbf{x}$, and $p$ move along the following transition paths from 1880 to 2020 :

$$
\mathbf{z}_{t}=\mathbf{z}_{1880} e^{\Delta \mathbf{z}(t-1880)}, \quad \mathbf{x}_{t}=\mathbf{x}_{1880} e^{\Delta \mathbf{x}(t-1880)}, \quad \text { and } \quad p_{t}=p_{1880} e^{\Delta p(t-1880)},
$$

for $t=1880, \cdots, 2020$. Here $\Delta \mathbf{z}>\mathbf{0}, \Delta \mathbf{x}>\mathbf{0}$, and $\Delta p<0$ are the net rates of change in these variables as reported in Table 6.1. ${ }^{20}$ The word "quasi" is used because in each period parents neglect to take into account that prices will be different in the

\footnotetext{
20 The productivity of child labor in the home also changes according to $\chi_{t}=\chi_{1880} e^{\Delta \chi(t-1880)}$, where
} $\Delta \chi \%=-0.224 \%$. Recall from Table 5.2 that $\chi_{1880}=0.015$ and $\chi_{1880}=0.11$. 

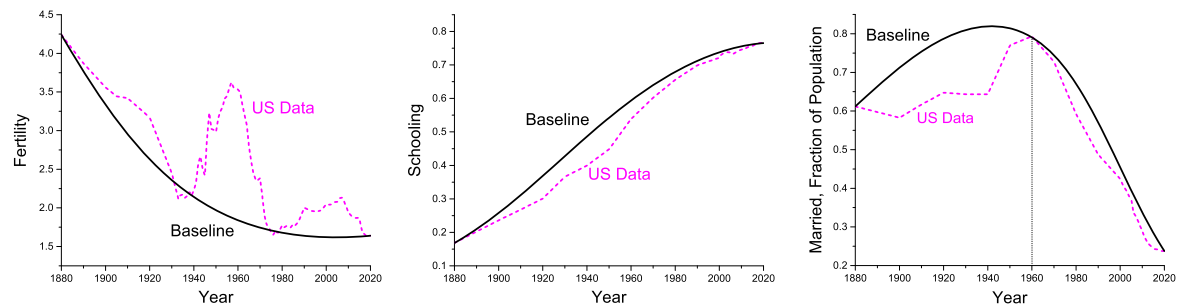

FIGURE 6.1 Transitional dynamics-fertility, schooling, and marriage.

subsequent period; i.e., they are myopic. Think about the transitional dynamics as a sequence of static equilibriums.

Fig. 6.1 illustrates how the baseline model's predictions for fertility, schooling, and marriage fair compared with the US data. Take fertility first, which is shown in the left panel. Abstracting from the baby boom, the model does well matching the secular decline in fertility displayed in the US data. The model also does a good job matching the rise in schooling (the middle panel). Move to the right panel. In the US data, marriage shows a $\cap$-shaped pattern over time. To replicate this pattern, the parameter $\sigma$, governing the degree of substitutability between durables and housework in the home production function, is chosen so that the model matches closely the fraction of the US population that was married in $1960 .{ }^{21}$ As reported in Table 5.2, the resulting value for $\sigma$ is 0.282 . What explains the $\cap$ shape? The utility benefit of marriage derived from the increased schooling for children climbs over time. So, early on there are gains from marriage. But, this utility benefit from schooling children is eventually eroded away; the hike in labor-saving durables implies that the utility in single life derived from home goods, leisure, and market goods rises relative to married life and comes to dominate in the later years. ${ }^{22}$

Some comparative dynamics are now performed. For each period from 1880 to 2020, the model is run under four scenarios: (1) A baseline scenario where all technology factors are operational (the results for baseline transitional dynamics discussed above), (2) an experiment where only changes in $\mathbf{z}$ are shut down, (3) a situation where $\mathbf{x}$ alone is unplugged, and (4) a case where $p$ is held fixed in isolation. Fig. 6.2 shows the comparative dynamics for fertility and schooling. It is immediately obvious that without skill-biased technological change (the Fixed $\mathbf{x}$ lines), fertility would rise and schooling fall. When either $\mathbf{z}$ or $p$ are shutdown, fertility still drops

\footnotetext{
21 To compute $\sigma$ another loop is added outside of the previous two loops in the calibration strategy described in Section 5. This outer loop minimizes the difference between the model's implied married population in 1960 and its data counterpart. The parameters values that are not assigned on the basis of direct information are functions of $\sigma$. So too are the sequences for $\mathbf{x}_{t}$ and $\mathbf{z}_{t}$. The sequences for $\chi_{t}$ and $p_{t}$ are exogenous.

22 The word relative is important as the utility from home goods, leisure, and market goods rises over the course of the century for both types of households.
} 

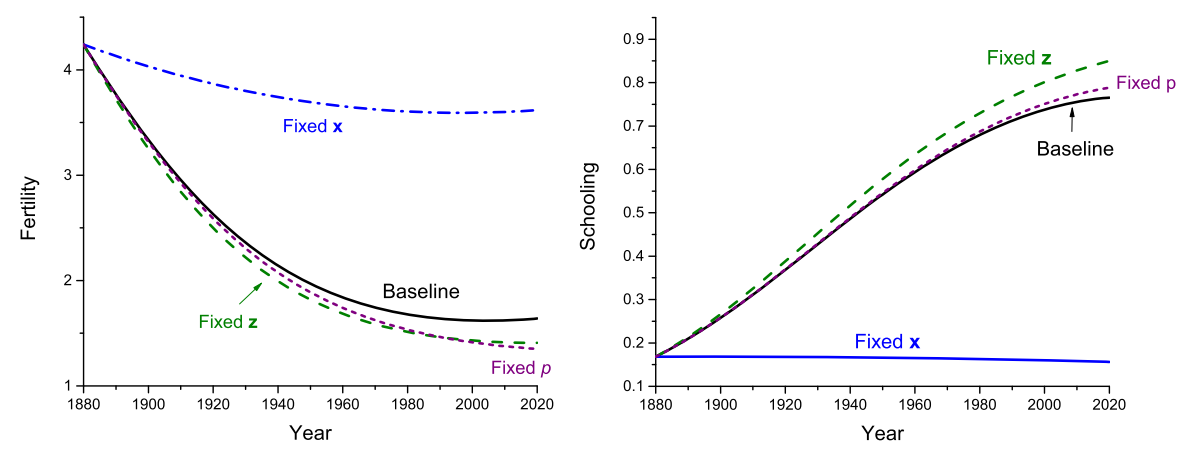

FIGURE 6.2 Comparative dynamics-fertility and schooling.
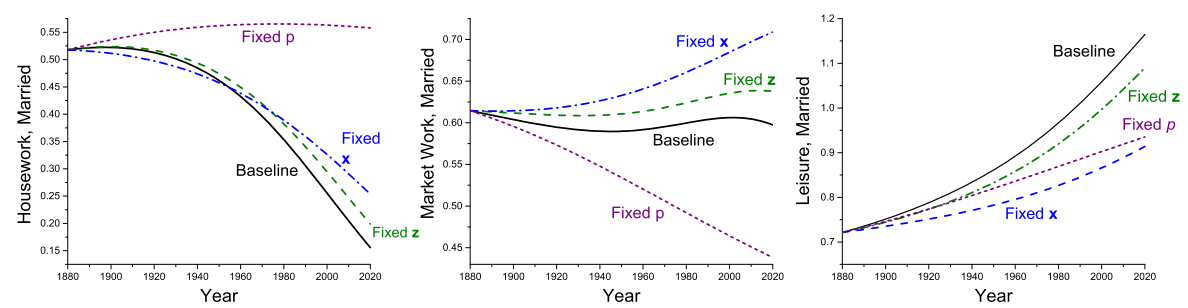

FIGURE 6.3 Comparative dynamics-housework, market work, and leisure.

and educational attainment picks up. For these two cases, the deviations from the baseline time path are modest.

The comparative dynamics for a married household's time allocations are displayed in Fig. 6.3. The time paths for single households (not shown) tell the same story. Focus on the lefthand panel. Clearly, process innovation in the production of labor-saving household durables is responsible for the decline in housework (the Fixed $p$ line). Without this, housework actually rises a little. As a married household becomes richer, they would like to consume more nonmarket goods, which requires either working more in the home or buying more labor-saving durables. The latter are still very expensive though. The impact of neutral technological progress, $\mathbf{z}$, or skill-biased technological change, $\mathbf{x}$, on housework is small. The middle panel demonstrates that process innovation in the production of labor-saving household durables is also important for market work; without it, there is a dramatic decline in market work. As living standards improve due to increases in $\mathbf{z}$ and $\mathbf{x}$, households demand more leisure-see the right panel. But, without technological progress in the home, this requires cutting back on market work. When either the neutral or skillbiased technology factors are switched off, households are much poorer. To make up for this, they must work more in the market relative to the baseline picture, as the middle panel illustrates-the Fixed $\mathbf{z}$ and $\mathbf{x}$ lines. As a consequence, the rise in leisure falls short of the baseline scenario as shown in the right panel. 


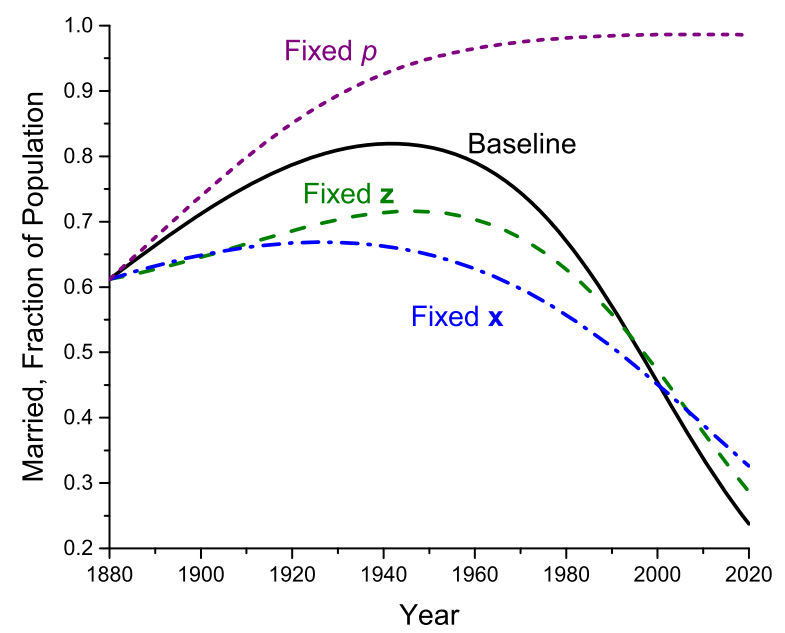

FIGURE 6.4 Comparative dynamics-marriage.

The last plot is for marriage, which is presented in Fig. 6.4. The primary driver of the decline in marriage is process innovation in the production of labor-saving household durables as the Fixed $p$ line demonstrates. The impact of $\mathbf{z}$ and $\mathbf{x}$ on marriage is negligible. When there is no decline in the price of durables, married households fare better relative to single ones because their consumption of home goods and leisure isn't squeezed as much.

\section{Ending}

A great transition in family structure occurred during the last century, both in the United States and the rest of the world. Family size became smaller as fertility dropped and marriage declined. Educational attainment rose giving rise to a shift toward white-collar occupations. The burden of housework eased tremendously. People enjoyed much more leisure than in the past. A macroeconomic model is advanced and calibrated to see if it can explain this set of Kuznets-style facts for the United States, and it can. One can think about the analysis as providing a user guide for formulating and calibrating macroeconomic models of the family.

The calibration strategy employed is closely linked with the economic intuition arising from the model. In particular, the exponents on the utility functions for leisure, nonmarket goods, the number of kids, and children's wages govern the rates of change in leisure, housework, fertility, and education, whereas the weights determine the levels for these variables in some baseline year. The first-order conditions for a married household's choice problem form the foundation for this theory-based identification strategy. These first-order conditions are also invaluable for understanding 
how the model reacts to technological progress in the economy. There may, of course, be other frameworks, and calibration strategies, that can explain the same set of facts. A virtue of the current setup is that it is parsimonious yet rich enough to explain the great transition.

What forces propelled the great transition? Three candidates are considered here: neutral technological progress, skill-biased technological change, and process innovation that lowered the price of labor-saving household durables. Quantitative analysis suggests that skill-biased technological change, reflecting a shift from brawn to brain, was instrumental in explaining the decline in fertility and the rise in educational attainment. This encouraged married households to have fewer, but more educated, kids. Process innovation that lowered the price of labor-saving household durables was key for deciphering both the decline in housework and marriage. Last, while neutral technological progress was important for rising living standards, it had a benign impact on family structure.

What is the next frontier for the macroeconomic approach to family? The changing structure of households around the world creates challenges for public policy. Macroeconomics is well suited to address public policy questions. The reason is that public policy has general equilibrium effects resulting from induced shifts in wages and the overall level of taxation needed to finance government programs. Some public policy challenges are: (1) Designing tax and transfer policies in economies where most married households consist of two potential earners-Gayle and Shephard (2019) and Guner et al. (2012, 2021a); (2) Developing family-friendly policies for firms and households-Bover et al. (2021), Erosa et al. (2010b), Xiao (2021); (3) Implementing welfare systems that take into consideration their effect on single parenthood, marriage, and investment in children-Greenwood et al. (2000), Low et al. (2020), and Mullins (2019); (4) Executing health care policies while factoring in household labor supply-Fang and Shephard (2019); (5) Encouraging fertility in developed countries with declining birth rates-Doepke and Kindermann (2019) and Guner et al. (2021b).

\subsection{Background material}

For an elementary introduction to family economics, see Greenwood (2019). This book emphasizes how technological progress has affected the family. It follows in the footsteps of a prescient monograph in sociology by Ogburn and Nimkoff (1955). A more advanced textbook on family economics is Browning et al. (2014). Two surveys on family economics from a macroeconomic perspective are Doepke and Tertilt (2016) and Greenwood et al. (2017). Time use is discussed in Aguiar and Hurst (2016). An examination of the economics of fertility is presented in Doepke et al. (2023). Chiappori (2020) and Chiappori and Salanié (2023) review the empirical and theoretical literature on marriage. Currently there are no surveys of the macroeconomics literature on education. Goldin and Katz (2008) provide a twentieth century history on education and wages in the United States. Some references to the macro literature on education are provided below. Taken together these sources 
provide extensive literature reviews. The review here is oriented toward discussing macroeconomic modeling of the Kuznets-style facts presented in Section 2.

\subsection{Hours worked}

As wages rose the average workweek in the market declined, as Figs. 2.1 and 2.3 exhibit. An elementary discussion of the long-run trend in hours worked is contained in Greenwood and Vandenbroucke (2008). They emphasize three mechanisms that have an effect on hours worked: real wages, leisure goods, and time-saving appliances. Quantitative explorations of the first two forces are in Vandenbroucke (2009) and Kopytov et al. (2020)-see also related work by Bick et al. (2021). The trend toward earlier retirement, presented in Fig. 2.5, is analyzed in Kopecky (2011) who models the impact of rising real wages and falling prices of leisure goods. The rise in female labor-force participation and the decline in housework is the subject of Greenwood et al. (2005b); see Figs. 2.1, 2.2, 2.3, and 2.4. The idea is that household appliances liberated women from the home and allowed them to enter the workforce. In a similar vein, Albanesi and Olivetti (2016) suggest that advances in maternal medicine facilitated the entry of married women with children into the labor force. At first, the increase in female labor-force participation might be slow because it takes time for attitudes to change and knowledge to spread, as suggested by the learning models of Fernandez (2013) and Fogli and Veldkamp (2011). A dynamic life-cycle model of female labor supply is estimated by Eckstein and Lifshitz (2011) to analyze the different drivers behind the rise in married female labor-force employment over the last 50 years. By their estimation, the rise in education levels accounts for 33 percent of the increase in wages and the narrowing of the gender wage gap accounts for another 20 percent, while about 40 percent remains unexplained by factors such as the declining cost of household maintenance.

Rising female labor-force participation allows married households to smooth income fluctuations. Blundell et al. (2016) find that only about one-third of permanent shocks to male wages and a fifth of permanent shocks to female wages are passed through to household consumption. This is closely related to the added-worker effect, an idea with a long history in labor economics-see, for example, Lundberg (1985). Wu and Krueger (2021) model how consumption smoothing arises in a model of joint labor supply decisions, while Bardoczy (2021) emphasizes the role of female labor supply as a mitigator of household income risk over the business cycles. De Nardi et al. (2021) and Guner et al. (2021a) study the role of taxes and transfers for consumption smoothing. Female employment is also less cyclical than male employment; at least, it was until the COVID-19 downturn as discussed in Alon et al. (2022). As a result, higher female labor-force participation made the recent recessions less cyclical (the so-called great moderation), a mechanism modeled by Albanesi (2019).

\subsection{Fertility}

The Razin and Ben-Zion (1975) model of fertility is modified here along the lines of Greenwood et al. (2005a, Section IV) to incorporate parental investment in chil- 
dren. This has the flavor of the famous Becker and Lewis (1973) tradeoff between the quality and quantity of children, but the brain-versus-brawn interpretation follows Galor and Weil (1996). Galor and Weil (1996) discuss how capital accumulation leads to a shift away from brawn toward brain in the labor market, which raises women's wages more than men's. Fertility declines as a consequence. Greenwood et al. (2005a) model the secular decline in fertility as well as the baby boom; recall Fig. 2.6. The long-run decline in fertility resulted from an increase in wages, which escalated the cost of having children. Delventhal et al. (2021) study demographic transitions across the world since the middle of the 18th century. The rise in skill premium is the key driver of decline in fertility in their analysis. Bar et al. (2018) argue that increasing inequality between 1980 and 2010 can explain the recent growth in US fertility among high-income households, as the time cost of their childcare can be more cheaply outsourced to workers who earn relatively lower wages. Relatedly, Hazan et al. (2021) find that this inequality and marketization of childcare costs mechanism can explain much of the convergence in US fertility between high-income women and other women among the extensive margin (a decline in childlessness among women ages 40 to 44 with advanced degrees), in addition to the intensive margin.

The analysis abstracts from the baby boom. Greenwood et al. (2005a) suggest that the baby boom was the result of technological progress in the home that economized on the need for labor. A complementary hypothesis is advanced by Albanesi and Olivetti (2014). They argue that advances in obstetric and pediatric medicines led to improvement in the health of new mothers and their children. Both hypotheses operate by reducing, in the middle of the 20th century, the time cost associated with having young children. This encouraged a baby boom. Doepke et al. (2015) link the baby boom to the poor job market conditions faced by young women immediately after World War II. This led to young women staying at home and having children. ${ }^{23}$ There is also no role for contraception or family planning policies in the current analysis, which are important for understanding fertility in developing countries, as modeled by Cavalcanti et al. (2021) and de Silva and Tenreyro (2020).

Last, the right panel of Fig. 2.7 shows that the percentage of women older than forty who are childless appears to rise with per capita GDP. Not much work has been done on this topic, but a recent example is by Baudin et al. (2015).

\subsection{Marriage}

The framework for marriage is adopted from Greenwood and Guner (2009), which was proceeded by Mortensen's (1988) prototype model of marriage. The Greenwood and Guner (2009) framework again incorporates the notion of household production à la Becker (1965) and Reid (1934). The hypothesis is that technological progress

\footnotetext{
23 On this, it should be noted that the baby boom started in some countries before World War II and also occurred in neutral Ireland, Sweden, and Switzerland. So, this hypothesis might need to be used in conjunction with the reduction in time cost hypotheses.
} 
in the home and rising living standards reduced the need for household labor. This raised the value of single life relative to marriage. Their analysis also addresses the transient decline in the fraction of the never-married population around World War II; i.e., the $\cup$-shaped pattern shown in Fig. 2.8. This is done by incorporating a decision for young adults to leave home. At first rising incomes and technological advance in the household sector allowed young adults to leave their parents' homes through marriage. As economic development continued, they could afford to leave home and live alone before getting married. The framework predicts that household size should decline with economic development, a fact displayed in Fig. 2.11.

The analysis here leaves several important issues untouched. First, marriage is a once-and-for-all decision in the model. Fernandez and Wong (2016) find that the introduction of unilateral divorce laws in the 1970s in the United States promoted divorce, increased married female labor-force participation, and reduced the gender wage gap. The impact of unilateral divorce and the equitable division of property on savings is studied in Voena (2015). In her model, equitable property division coupled with unilateral divorce lowers couples' incentives to save and encourages female labor-force participation.

Second, there can be rich interactions between labor and marriage markets. Santos and Weiss (2016) link the decline in marriage in recent decades to growing income risk. Since marriage might imply consumption commitments, it becomes less attractive with more volatile incomes. ${ }^{24}$ Blacks in the United States are much less likely to be married than whites. Caucutt et al. (2021) suggest that blacks' bleak employment opportunities and high incarceration rates, which make black males much more risky husbands, can account for the racial marriage gap. Calvo et al. (2021) study how the nature of home production, in particular whether the home hours of husbands and wives are complements or substitutes, affects sorting in marriage and labor markets.

Third, the analysis abstracts from heterogeneity in attitudes towards marriage and female labor supply. Attitudes are introduced into a model of marriage and divorce by Goussé et al. (2017). They find that they play an important role for the allocation of housework between husbands and wives.

Finally, the analysis also abstracts from cohabitation and how couples might sort into different arrangements. As also shown in Fig. 2.8, the fraction of young nevermarried women who are cohabiting has increased in recent years. Gemici and Laufer (2011) study how decisions to marry or cohabit are affected by divorce costs. Incentives to invest in children might also differ between married and cohabiting couples, as addressed by Adamopoulou et al. (2021).

24 Sommer (2016) argues that a similar effect operates on fertility. Relatedly, Vandenbroucke (2014) suggests that the drop in French fertility during World War I was not caused by missing men, but rather was due to the fact that fathers might be killed or maimed in the war. 


\subsection{Household size}

Fig. 2.11 shows that households size is negatively associated with economic development. As discussed above, the Greenwood and Guner (2009) model of marriage and divorce predicts a decline in household size as more young people choose to leave home and live life as singles. The fall in household size is also modeled in Salcedo et al. (2012), who suggest that as incomes rose so did the demand for privacy. Bethencourt and Rios-Rull (2009) present a similar story for elderly widows. Pensieroso and Sommacal (2019) argue that the shift from agriculture to industry is an important factor for explaining the drop in intergenerational coresidence.

\subsection{Education and occupations}

The brain-versus-brawn framework adopted here, which is used to explain the trends in occupational choice illustrated by Figs. 2.14 and 2.15, can be thought of as a descendant of Ben-Porath (1967). The brain-versus-brawn framework is operationalized in the current work via skill-biased technological change. A modern quantitative model of schooling in the United States is provided in Restuccia and Vandenbroucke (2014), which contains references to the literature; a similar model is constructed by Castro and Coen-Pirani (2016). Restuccia and Vandenbroucke (2014) is in the spirit of Kuznets (1957). They explain both the cross-sectional and time-series facts regarding educational attainment shown in Figs. 2.12 and 2.13, as well as the patterns of average hours worked displayed in Figs. 2.1 and 2.3. In their analysis schooling enters the utility function as it does here. As incomes rise so do the demands for education and leisure. Erosa et al. (2010a) and Manuelli and Seshadri (2014) focus on explaining cross-country facts surrounding education, especially differences in incomes across countries.

Another significant change over the last century is the rise in life expectancy, which some have argued is an important factor driving the increase in schooling. Cervellati and Sunde $(2013,2015)$ argue that such a relationship existed for the United States in the 1940s and show in a life-cycle model that an increase in life expectancy can lead to additional years of schooling without the need for an increase in labor supply. ${ }^{25}$ Restuccia and Vandenbroucke (2014) also find that life expectancy partially explains differences in educational attainment across countries and over time. Soares (2005) shows that declines in child mortality and increases in adult longevity can trigger drops in fertility and hikes in schooling. For an early analysis about how technological progress in medicine leads to a rise in health-care spending and longer life expectancy, see Suen (2006).

Beyond the brain-versus-brawn distinction, occupations differ along other dimensions. Goldin (2014) emphasizes the inflexibility of some high-paying occupations, defined as requirements to work long and particular hours, as a barrier to female

\footnotetext{
25 Hazan (2009) argues that an increase in labor supply is a necessary condition for longer life expectancy to drive a rise in schooling.
} 
participation in such careers and as a factor for a higher observed gender wage gap. Erosa et al. (2022) model how such inflexibility, together with gender differences in housework, leads to gender gaps in occupational choices, wages, and hours worked. If occupations differ in their flexibility and men and women value such amenities differently, they are likely to select into occupations accordingly. Furthermore, firms might be less likely to hire women for particular jobs if the impact of labor market interruptions is higher for women, such as due to childrearing. Flabbi and Moro (2012), Morchio and Moser (2021), and Xiao (2021) study such interactions in models of labor market search.

\section{Appendix A Data appendix}

- Fig. 2.1 (average weekly hours and labor-force participation in the United States): The source for average weekly hours, "All”, is Vandenbroucke (2009, Figure 1). This series covers the period 1830 to 2000. Prior to 1940 , the data cover all workers, and after that it refers to workers ages 15 and above. The series for men between 1900 and 1930 is also from Vandenbroucke (2009, Figure 1) and is spliced together with US Census data for the subsequent years. The numbers for men and women from 1940 to 2018 correspond to the 20-to-64 age group (conditional on being employed and reporting positive hours) and are taken from the US Decennial Censuses, 1940-2000, and the American Community Survey (ACS) after that. The labor-force participation numbers were derived from the US Decennial Censuses, 1860-2000, and the ACS thereafter. They refer to individuals ages 20 to 64. Both series are taken from the Integrated Public Use Microdata Series (IPUMS) and exclude households with institutionalized individuals. Only household heads and spouses are considered. The series are weighted means. The series marked "All" averages across both men and women.

- Fig. 2.2 (housework in the United States): The source for the data on housework (cleaning, cooking, and laundry) from 1900 to 1926 is Lebergott (1993, Table 8.1). Lebergott's number of 58 hours per week of housework in 1900 is somewhat speculative. Articles in women's magazines, such as Ladies Home Journal in 1920, suggested a similar number-see Greenwood (2019, p. 51). Lebergott's figure of 36 hours for 1925-1927 is close to the Gershuny and Harms (2016, Figure 1) estimate of 37 hours. In fact, if one adds in time spent knitting, mending, and sewing then the Gershuny and Harms (2016) number rises to 43 hours. The numbers for 1965 to 2019 represent core housework and meal preparation (ATUS household activities 0201 and 0202) for women ages 20 to 64. The data are taken from the American Heritage Time Use Survey (up to 1993) and from the American Time Use Survey (since 2003), available through the US Bureau of Labor Statistics. It excludes students, retirees, and all individuals who do not report their gender, age, or education level, as well as those whose total weekly hours are different than 168 hours per week (or 24 hours per day). The series are weighted means. 
- Fig. 2.3 (the cross-country relationship between per-capita GDP and hours worked, both in the market and at home): The hours-worked data for 46 countries are taken from Bick et al. (2018, Figure 1), where each country has a single observation within a few years from 2005. The source for the data on hours spent cleaning and cooking is Bridgman et al. (2018, Figure 9). They focused on 54 countries; different countries had a different set of years for the observations spanning from 1974 to 2012. Bick et al. (2018) use real GDP per capita for the same years as hours worked. GDP per capita is measured in US\$2011 (expenditure side PPP terms from the Penn World Tables). Bridgman et al. (2018) utilize real GDP per capita measured in US\$1990 for various years (in PPP terms from the Conference Board). This explains the difference in the horizontal axes.

- Fig. 2.4 (the cross-country rise in female labor-force participation): The data pertain to women in the 20-to-64 age group. The numbers for female labor-force participation are taken from the OECD's Labor Force Statistics while those for per-capita GDP, measured in purchasing power parity (PPP) international \$2017, come from The World Bank. The scatter diagram shows the relationship between per-capita GDP and female labor-force participation for 50 countries for the years 1990 to 2019; some early years are missing for some countries. The time-series graph plots the data for Australia (1966-2019), Germany (1970-2019), Ireland (1971, 1975, 1977, 1981, 1983-2019), Italy (1970-2019), South Korea (19802019), Mexico (1991-2019), and Spain (1972-2019).

- Fig. 2.5 (the trend toward earlier retirement): All numbers pertain to men. For the United States, retirement for each age group is defined as not being in the labor force. The American data span the years 1850 to 2018. The sources for the 1850-2000 period are the US Decennial Censuses, and the source for the 2001 to 2018 period is the ACS, all taken from IPUMS. The series are weighted means. The cross-country retirement data are for men ages 65+ across 186 countries and come from the International Labor Organization (ILO), Labor Force Participation by Sex and Age. GDP per capita is taken from The World Bank and is measured in PPP terms in international \$2017. The range of years plotted for each country differs but lies somewhere between 1990 and 2020.

- Fig. 2.6 (fertility in the United States): The numbers refer to the total fertility rate for white women ages 10 to 49. Data for women of all races only started in 1905 and then are continuously recorded starting in 1933. The figure is almost indistinguishable if all races are included after 1933. The total fertility rate is the sum of birth rates for five-year age groups (ages 10-14, 15-19, 20-24, 25-29, 30$34,35-39,40-44,45-49)$ multiplied by 5. For 1800 to 1990 , the data are from Carter et al. (2006, Series Ab52 and Ab63). For the years 1991 to 2009, the data come from Martin et al. (2017, Table 4), while for 2010 to 2019 the source is Martin et al. (2021, Table 2).

- Fig. 2.7 (the cross-country decline in fertility): Here the relationship between real per-capita GDP (logged) and the total fertility rate is shown for 185 countries for the years 1990, 1995, 2000, 2005, 2010, and 2015. The set of years varies across countries. The total fertility rate is the sum of birth rates for five-year age 
groups (ages 15-19, 20-24, 25-29, 30-34, 35-39, 40-44, 45-49) multiplied by 5 . The source for the data on the total fertility rate is the United Nations, World Fertility Data 2019. Real per-capita GDP is taken from The World Bank, and is measured in PPP terms in international \$2011. The time series decline in the crude birth rate is plotted for Argentina (1862-2016), Iran (1953-2016), South Korea (1953-2016), Mexico (1895-2016), Portugal (1886-2016), Thailand (1953-2016), and the United Kingdom (1850-2016). The data were collected by Delventhal et al. (2021), who report the underlying sources. The figure also shows the crosscountry relationship between GDP and childlessness. The childlessness data are for 33 countries, surveyed in the mid-1990s and around 2010. The source for the data on the fraction of women ages 40 to 44 who have not had a live birth is the OECD's Family Database. Real GDP per capita, measured in PPP terms in international \$2017, is taken from The World Bank.

- Fig. 2.8 (marriage in the United States): The source for the data on the fraction of the female population, ages 20 to 29, that was never married is the US Decennial Census for the years 1880 to 2000. The data for 2001-2019 are based on the ACS. Both are retrieved from IPUMS. The calculation excludes individuals who are separated, divorced, or widowed. The series is a weighted mean. The figure also shows a plot netting out the fraction of the never-married who are cohabiting, using a cohabitation series constructed by Adamopoulou et al. (2021) for 20-to29 year-old women based on Annual Social and Economic Supplement (ASEC) data. The median age at first marriage, for the period 1880 to 2019, is harvested from the United States Census Bureau's Historical Marital Status Tables, Table MS-2.

- Fig. 2.9 (composition of households in the United States): The sources for the data on living arrangements are the US Decennial Censuses, 1900-2000, and from the ACS, for 2010 and 2019. The "Other" category refers to households with unrelated individuals living together.

- Fig. 2.10 (the cross-country relationship between GDP and marriage): The facts for marriage are plotted for 196 countries from 1990 to 2019; the set of years varies across countries. The fraction of women ages 20 to 24 that were never married and the mean age at marriage at first marriage are taken from the United Nations, World Marriage Data (2019). The source for the real GDP per capita is The World Bank, measured in PPP terms in international \$2011.

- Fig. 2.11 (household size in the United States and across countries): The US data spanning 1850 to 1950 are sourced from Carter et al. (2006, Series Ae79 and Ae85). From 1960 to 2019, the data are contained in the US Census Bureau's Historical Household Tables (Table HH-4). The cross-country data are for 151 countries, where each country has a set of observations for some years between 1990 and 2018. They come from the United Nations, Household Size and Composition Database. Real per-capita GDP is taken from The World Bank, measured in PPP terms in international \$2011. The cross-country relationship between GDP and three-generation households is also shown. The data on three-generation households cover 106 countries from 1990 to 2018. The source for the data on the 
fraction of households that are three-generation households is the United Nations, Department of Economic and Social Affairs, Population Division (2019c). Real GDP per capita, measured in PPP terms in international \$2017, is taken from The World Bank.

- Fig. 2.12 (educational attainment in the United States): The data on years of schooling for whites at age 35, by birth cohorts from 1876 to 1975, are from Goldin and Katz (2008, Figure 1.4). Enrollment in institutions of higher education as a percentage of the 18-to-24 year old population, for the years 1869-1995, is provided in Carter et al. (2006, Series Bc524).

- Fig. 2.13 (the cross-country relationship between GDP and educational attainment): The data are for 112 countries, where a country reports some subset of years in the set $\{1990,1995,2000,2005,2010\}$. The source for the data on years of schooling and completed tertiary education is Lee and Lee (2016). Real GDP per capita, measured in PPP terms in international \$2017, comes from The World Bank.

- Fig. 2.14 (occupations in the United States): The data span the period 1860 to 2018. They show the percentage of the labor force for each gender, ages 18 to 64 , working in blue- and white-collar jobs. The sources for the 1850-2000 period are the US Decennial Censuses and the source for the 2001 to 2018 period is the ACS, all taken from IPUMS. White-collar jobs comprise the managerial and professional specialty occupations as well as the technical, sales, and administrative support occupations. Blue-collar jobs comprise the services occupations, the farming, forestry, and fishing occupations, the precision production, craft, and repair occupations, and the operators, fabricators, and laborers occupations. This classification follows the ILO's ISCO categories.

- Fig. 2.15 (the cross-country relationship between per-capita GDP and white-collar jobs): The data cover 186 countries for years 2010 to 2018. Not all countries had the data for all years. The data on white-collar jobs as a percentage of all jobs for a given gender are reaped from the ILO, Employment by Sex and Occupation. GDP per capita is measured in PPP terms in international \$2017 is taken from The World Bank.

\section{References}

Abbott, E., 1908. A study of the early history of child labor in America. American Journal of Sociology 14 (1), 15-37.

Acemoglu, D., Autor, D., 2011. Skills, tasks and technologies: implications for employment and earnings. In: Card, D., Ashenfelter, O. (Eds.), Handbook of Labor Economics, vol. 4B. Elsevier B.V., Amsterdam, pp. 1043-1171.

Adamopoulou, E., Hannusch, A., Kopecky, K., Obermeier, T., 2021. Rising Cohabitation and Child Development. Federal Reserve Bank of Atlanta. Unpublished paper.

Aguiar, M., Hurst, E., 2016. The macroeconomics of time allocation. In: Taylor, J.B., Uhlig, H. (Eds.), Handbook of Macroeconomics, vol. 2A. Elsevier B.V., Amsterdam, pp. 203-253. 
Albanesi, S., 2019. Changing Business Cycles: the Role of Women's Employment. NBER Working Paper 25655.

Albanesi, S., Olivetti, C., 2014. Maternal health and the baby boom. Quantitative Economics 5 (2), 225-269.

Albanesi, S., Olivetti, C., 2016. Gender roles and medical progress. Journal of Political Economy 124 (3), 650-695.

Alon, T., Coskun, S., Doepke, M., Koll, D., Tertilt, M., 2022. From mancession to shecession: women's employment in regular and pandemic recessions. NBER Macroeconomics Annual 2021 (36), 83-151.

Bar, M., Hazan, M., Leukhina, O., Weiss, D., Zoabi, H., 2018. Why did rich families increase their fertility? Inequality and the marketization of child care. Journal of Economic Growth 23 (4), 427-463.

Bardoczy, B., 2021. Spousal Insurance and the Amplification of Business Cycles. Federal Reserve Board. Unpublished paper.

Baudin, T., de la Croix, D., Gobbi, P., 2015. Fertility and childlessness in the United States. American Economic Review 105 (6), 1852-1882.

Becker, G.S., 1965. A theory of the allocation of time. Economic Journal 75 (September), 493-517.

Becker, G.S., 1973. A theory of marriage: part I. Journal of Political Economy 81 (4), 813-846.

Becker, G.S., 1991. A Treatise on the Family, enlarged edition. Harvard University Press, Cambridge, MA.

Becker, G.S., Lewis, H.G., 1973. On the interaction between the quantity and quality of children. Journal of Political Economy 81 (2, Part 2), S279-S288.

Ben-Porath, Y., 1967. The production of human capital and the life cycle of earnings. Journal of Political Economy 75 (4, Part 1), 352-365.

Bethencourt, C., Rios-Rull, J.V., 2009. On the living arrangements of elderly widows. International Economic Review 50 (3), 773-801.

Bick, A., Fuchs-Schundeln, N., Lagakos, D., 2018. How do hours worked vary with income? Cross-country evidence and implications. American Economic Review 108 (1), 170-199.

Bick, A., Fuchs-Schundeln, N., Lagakos, D., Tsujiyama, H., 2021. Structural Change in Labor Supply and Cross-Country Differences in Hours Worked. NBER Working Paper 29099.

Bils, M.J., Kaymak, B., Wu, K.-J., 2020. Labor Substitutability among Schooling Groups. University of Rochester. Unpublished paper.

Blundell, R., Pistaferri, L., Saporta-Eksten, I., 2016. Consumption inequality and family labor supply. American Economic Review 106 (2), 387-435.

Bover, O., Guner, N., Kulikova, Y., Ruggieri, A., Sanz, C., 2021. Family-Friendly Policies and Fertility: What Firms Got to Do With It? University of Nottingham. Unpublished paper.

Bridgman, B., Duernecker, G., Herrendorf, B., 2018. Structural transformation, marketization, and household production around the world. Journal of Development Economics 133, 102-126.

Browning, M., Chiappori, P.A., Weiss, Y., 2014. Economics of the Family. Cambridge University Press, New York, NY.

Bureau of Foreign and Domestic Commerce, 1934. National Income, 1929-32. United States Government Printing Office, Washington.

Calvo, Paula, Lindenlaub, Ilse, Reynoso, Ana, 2021. Marriage Market and Labor Market Sorting. NBER Working Paper 2888.

Carter, S.B., Gartner, S.S., Haines, M.R, Olmstead, A.L., Sutch, R., Wright, G., 2006. Historical Statistics of the United States, millennial edition. Cambridge University Press, New York. 
Castro, R., Coen-Pirani, D., 2016. Explaining the evolution of educational attainment in the United States. American Economic Journal: Macroeconomics 8 (3), 77-112.

Caucutt, E., Guner, N., Rauh, C., 2021. Is Marriage for White People? Incarceration, Unemployment, and the Racial Marriage Divide. CEMFI Working Paper 2016.

Cavalcanti, T., Kocharkov, G., Santos, C., 2021. Family planning and development: aggregate effects of contraceptive use. The Economic Journal 131 (634), 624-657.

Cervellati, M., Sunde, U., 2013. Life expectancy, schooling, and lifetime labor supply: theory and evidence revisited. Econometrica 81 (5), 2055-2086.

Cervellati, M., Sunde, U., 2015. The effect of life expectancy on education and population dynamics. Empirical Economics 48 (4), 1445-1478.

Chiappori, P.A., 1988. Rational household labor supply. Econometrica 56 (1), 63-89.

Chiappori, P.A., 2020. The theory and empirics of the marriage market. Annual Review of Economics 12, 547-578.

Chiappori, P.A., Mazzocco, M., 2017. Static and intertemporal household decisions. Journal of Economic Literature 55 (3), 985-1045.

Chiappori, P.A., Costa Dias, M., Meghir, C., 2020. Changes in Assortative Matching: Theory and Evidence for the US. Cowles Foundation Discussion Paper no. 2226.

Chiappori, P.A., Salanié, B., 2023. Mating markets. In: Lundberg, S., Voena, A. (Eds.), Handbook of the Economics of the Family. Elsevier, Amsterdam. Chapter 2 (this volume).

De Nardi, M., Fella, G., Paz-Pardo, G., 2021. Wage Risk and Government and Spousal Insurance. NBER Working Paper 28294.

de Silva, T., Tenreyro, S., 2020. The fall in global fertility: a quantitative model. American Economic Journal: Macroeconomics 12 (3), 77-109.

Delventhal, M., Fernandez-Villaverde, J., Guner, N., 2021. Demographic Transitions across Time and Space. Claremont McKenna College. Unpublished paper.

Doepke, M., Hannusch, A., Kinderman, F., Tertilt, M., 2023. The economics of fertility: a new era. In: Lundberg, S., Voena, A. (Eds.), Handbook of the Economics of the Family. Elsevier, Amsterdam. Chapter 4 (this volume).

Doepke, M., Hazan, M., Maoz, Y.D., 2015. The baby boom and World War II: a macroeconomic analysis. The Review of Economic Studies 82 (3), 1031-1073.

Doepke, M., Tertilt, M., 2016. Families in macroeconomics. In: Taylor, J.B., Uhlig, H. (Eds.), Handbook of Macroeconomics, vol. 2B. Elsevier B.V., Amsterdam, pp. 1789-1891.

Doepke, M., Kindermann, F., 2019. Bargaining over babies: theory, evidence, and policy implications. American Economic Review 109 (9), 3264-3306.

Eckstein, Z., Lifshitz, O., 2011. Dynamic female labor supply. Econometrica 79 (6), 1675-1726.

Erosa, A., Koreshkova, T., Restuccia, D., 2010a. How important is human capital? A quantitative theory assessment of world income inequality. The Review of Economic Studies 7 (4), $1421-1449$.

Erosa, A., Fuster, L., Restuccia, D., 2010b. A general equilibrium analysis of parental leave policies. Review of Economic Dynamics 13 (4), 742-758.

Erosa, A., Fuster, L., Kambourov, G., Rogerson, R., 2022. Hours, occupations, and gender differences in labor market outcomes. American Economic Journal: Macroeconomics 14 (3), 543-590.

Fang, H., Shephard, A., 2019. Household Labor Search, Spousal Insurance, and Health Care Reform. NBER Working Paper 26350.

Fernandez, R., 2013. Cultural change as learning: the evolution of female labor force participation over a century. American Economic Review 103 (1), 472-500. 
Fernandez, R., Wong, J.C., 2016. Free to leave? A welfare analysis of divorce regimes. American Economic Journal: Macroeconomics 9 (3), 72-115.

Flabbi, L., Moro, A., 2012. The effect of job flexibility on female labor market outcomes: estimates from a search and bargaining model. Journal of Econometrics 168 (1), 81-95.

Fogli, A., Veldkamp, L., 2011. Nature or nurture? Learning and the geography of female labor force participation. Econometrica 79 (4), 1103-1138.

Galor, O., Weil, D.N., 1996. The gender gap, fertility, and growth. American Economic Review 86 (3), 374-387.

Gayle, G.L., Shephard, A., 2019. Optimal taxation, marriage, home production, and family labor supply. Econometrica 87 (1), 291-326.

Gemici, A., Laufer, S., 2011. Marriage and Cohabitation. Royal Holloway. Unpublished paper.

Gershuny, J., Harms, T.A., 2016. Housework now takes much less time: 85 years of US rural women's time use. Social Forces 95 (2), 503-524.

Goldin, C., 2014. A grand gender convergence: its last chapter. American Economic Review 104 (4), 1091-1119.

Goldin, C., Katz, L., 2002. The power of the pill: oral contraceptives and women's career and marriage decisions. Journal of Political Economy 110 (4), 730-770.

Goldin, C., Katz, L.F., 2008. The Race Between Education and Technology. The Belknap Press of Harvard University Press, Cambridge, MA.

Goussé, M., Jacquemet, N., Robin, J.M., 2017. Marriage, labor supply, and home production. Econometrica 85 (6), 1873-1919.

Greenwood, J., 2019. Evolving Households: The Imprint of Technology on Life. The MIT Press, Cambridge, MA.

Greenwood, J., Guner, N., 2009. Marriage and divorce since World War II: analyzing the role of technological progress on the formation of households. NBER Macroeconomics Annual 2008 (23), 231-276.

Greenwood, J., Guner, N., Knowles, J.A., 2000. Women on welfare: a macroeconomic analysis. The American Economic Review: Papers and Proceedings 90 (2), 383-388.

Greenwood, J., Guner, N., Knowles, J.A., 2003. More on marriage, fertility, and the distribution of income. International Economic Review 44 (3), 827-862.

Greenwood, J., Guner, N., Kocharkov, G., Santos, C., 2016. Technology and the changing family: a unified model of marriage, divorce, educational attainment, and married female labor-force participation. American Economic Journal: Macroeconomics 8 (1), 1-41.

Greenwood, J., Guner, N., Kopecky, K., 2021. The wife's protector: a quantitative theory linking contraceptive technology with the decline in marriage. In: Bison, A., Giovanni, F. (Eds.), The Handbook of Historical Economics. Academic Press, Elsevier, Amsterdam, pp. 903-943.

Greenwood, J., Guner, N., Vandenbroucke, G., 2017. Family economics writ large. Journal of Economic Literature 55 (4), 1346-1434.

Greenwood, J., Seshadri, A., Vandenbroucke, G., 2005a. The baby boom and baby bust. American Economic Review 95 (1), 183-207.

Greenwood, J., Seshadri, A., Yorukoglu, M., 2005b. Engines of liberation. The Review of Economic Studies 72 (1), 109-133.

Greenwood, J., Vandenbroucke, G., 2008. Hours worked (long-run trends). In: Blume, L.E., Durlauf, S.N. (Eds.), The New Palgrave Dictionary of Economics, vol. 4, 2nd ed. Palgrave Macmillan, New York, N.Y., pp. 75-81.

Guner, N., Kaygusuz, R., Ventura, G., 2012. Taxation and household labor supply. The Review of Economic Studies 79 (3), 1113-1149. 
Guner, N., Kaygusuz, R., Ventura, G., 2021a. Rethinking the Welfare State. CEPR Discussion Paper DP16275.

Guner, N., Kaya, E., Sanchez-Marcos, V., 2021b. Labor Market Institutions and Fertility. CEMFI. Unpublished paper.

Hazan, M., 2009. Longevity and lifetime labour supply: evidence and implications. Econometrica 77 (6), 1829-1863.

Hazan, M., Weiss, D., Zoabi, H., 2021. Marketization and the Fertility of Highly Educated Women along the Extensive and Intensive Margins. CEPR Discussion Paper DP16647.

Hofferth, S.L., Sandberg, J.F., 2001. How American children spend their time. Journal of Marriage and the Family 63 (2), 295-308.

Kopecky, K.A., 2011. The trend in retirement. International Economic Review 52 (2), 287-316.

Kopytov, A., Roussanov, N., Taschereau-Dumouchel, M., 2020. Cheap Thrills: the Price of Leisure and the Global Decline in Work Hours. University of Pennsylvania. Unpublished paper.

Kuznets, S., 1957. Quantitative aspects of the economic growth of nations: II. Industrial distribution of national product and labor force. Economic Development and Cultural Change 5 (4 supp), 1-111.

Lebergott, S., 1964. Manpower in Economic Growth: The American Record Since 1800. McGraw-Hill Book Company, New York.

Lebergott, S., 1993. Pursuing Happiness: American Consumers in the Twentieth Century. Princeton University Press, Princeton, NJ.

Lee, J.-W., Lee, H., 2016. Human capital in the long run. Journal of Development Economics 122 (September), 147-169.

Low, H., Meghir, C., Pistaferri, L., Voena, A., 2020. Marriage, Labor Supply and the Dynamics of the Social Safety Net. Stanford University. Unpublished paper.

Lundberg, S., 1985. The added worker effect. Journal of Labor Economics 3 (1), 11-37.

Lundberg, S., Pollak, R.A., 1993. Separate spheres bargaining and the marriage market. Journal of Political Economy 101 (6), 988-1010.

Lundberg, S., Pollak, R.A., Wales, T., 1997. Do husbands and wives pool their resources? Evidence from the UK child benefit. The Journal of Human Resources 32 (3), 463-480.

Manser, M., Brown, M., 1980. Marriage and household decision-making: a bargaining analysis. International Economic Review 21 (1), 31-44.

McElroy, M.B., Horney, M.J., 1981. Nash-bargained household decisions: toward a generalization of the theory of demand. International Economic Review 22 (2), 333-349.

Manuelli, R.E., Seshadri, A., 2014. Human capital and the wealth of nations. American Economic Review 104 (9), 2736-2762.

Martin, J.A., Hamilton, B.E., Osterman, M.J.K., Driscoll, A.K., Mathews, T.J., 2017. Births: Final Data for 2015. National Vital Statistics Reports 66 (1). National Center for Health Statistics, Hyattsville, MD.

Martin, J.A., Hamilton, B.E., Osterman, M.J.K., Driscoll, A.K., 2021. Births: Final Data for 2019. National Vital Statistics Reports 70 (2). National Center for Health Statistics, Hyattsville, MD.

McGrattan, E.R., Rogerson, R., Wright, R., 1997. An equilibrium model of the business cycle with household production and fiscal policy. International Economic Review 38 (2), 267-290.

McLanahan, S., Sandefur, G., 1994. Growing up with a Single Parent: What Hurts and What Helps. Harvard University Press, Cambridge and London. 
Mincer, J., 1958. Investment in human capital and personal income distribution. Journal of Political Economy 66 (4), 281-302.

Morchio, I., Moser, C., 2021. The Gender Pay Gap: Micro Sources and Macro Consequences. CEPR Discussion Paper DP16383.

Mortensen, D.T., 1988. Matching: finding a partner for life or otherwise. American Journal of Sociology 94 (suppl.), S215-S240.

Mullins, J., 2019. Designing Cash Transfers in the Presence of Children's Human Capital Formation. University of Minnesota. Unpublished paper.

Ngai, L.R., Petrongolo, B., 2017. Gender gaps and the rise of the service economy. American Economic Journal: Macroeconomics 9 (4), 1-44.

Ogburn, W.F., Nimkoff, M.F., 1955. Technology and the Changing Family. Houghton Mifflin, Boston, MA.

Pensieroso, L., Sommacal, A., 2019. Agriculture to industry: the end of intergenerational coresidence. Review of Economic Dynamics 34 (October), 87-102.

Ramey, V.A., Francis, N., 2009. A century of work and leisure. American Economic Journal: Macroeconomics 1 (2), 189-224.

Razin, A., Ben-Zion, U., 1975. An intergenerational model of population growth. American Economic Review 65 (5), 923-933.

Reid, M.G., 1934. Economics of Household Production. John Wiley \& Sons, Inc, New York, NY.

Rendall, M., 2018. Female market work, tax regimes, and the rise of the service sector. Review of Economic Dynamics 28 (2), 269-289.

Restuccia, D., Vandenbroucke, G., 2014. Explaining educational attainment across countries and over time. Review of Economic Dynamics 17 (4), 824-841.

Salcedo, A., Schoellman, T., Tertilt, M., 2012. Families as roommates: changes in U.S. household size from 1850 to 2000. Quantitative Economics 3 (1), 122-175.

Santos, C., Weiss, D., 2016. Why not settle down already? A quantitative analysis of the delay in marriage. International Economic Review 57 (2), 425-452.

Soares, R., 2005. Mortality reductions, educational attainment, and fertility choice. American Economic Review 95 (3), 580-601.

Sommer, K., 2016. Fertility choice in a life cycle model with idiosyncratic uninsurable earnings risk. Journal of Monetary Economics 83 (C), 27-38.

Suen, R.M.H., 2006. Technological Advance and the Growth in Health Care. University of Leicester. Unpublished paper.

Vandenbroucke, G., 2009. Trends in hours: the U.S. from 1900 to 1950. Journal of Economic Dynamics and Control 33 (1), 237-249.

Vandenbroucke, G., 2014. Fertility and wars: the case of World War I in France. American Economic Journal: Macroeconomics 6 (2), 108-136.

Voena, A., 2015. Yours, mine, and ours: do divorce laws affect the intertemporal behavior of married couples? American Economic Review 105 (8), 2295-2332.

Webbink, E., Smits, J., De Jong, E., 2012. Hidden child labor: determinants of housework and family business work of children in 16 developing countries. World Development 40 (3), 631-642.

Williamson, J.G., 1995. The evolution of global labor markets since 1830: background evidence and hypotheses. Explorations in Economic History 32 (2), 141-196.

Wu, C., Krueger, D., 2021. Consumption insurance against wage risk: family labor supply and optimal progressive income taxation. American Economic Journal: Macroeconomics 13 (1), 79-113.

Xiao, P., 2021. Wage and Employment Discrimination by Gender in Labor Market Equilibrium. Duke University. Unpublished paper. 